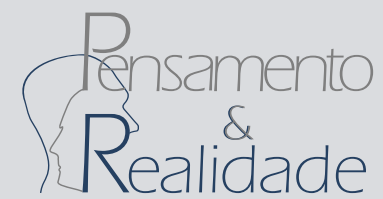

\title{
ESTRATÉGIAS PROVÁVEIS DOS PROGRAMAS DE STRICTO SENSU DO BRASIL FRENTE AO CENÁRIO OTIMISTA PROSPECTADO DE 2019 A 2030
}

\section{Henrique César Melo Ribeiro ${ }^{1}$ Sergio Henrique Arruda Cavalcante Forte}

\section{Resumo}

O objetivo deste estudo foi identificar as estratégias mais prováveis pelos Programas de Stricto Sensu das Instituições de Ensino Superior do Brasil da área de Administração Pública e de Empresas, Ciências Contábeis e Turismo frente ao cenário otimista prospectado para o período de 2019 a 2030, embasada pela metodologia sugerida por Blanning e Reinig (1998). Usou-se também a estatística descritiva e análise de agrupamento, mediante análise de conglomerados. Os resultados basilares mostram que, quanto à utilização média das estratégias e quanto ao uso extremo das estratégias, a estratégia "fomentar a qualidade das teses e das dissertações" ficou em destaque no cenário otimista. Enfocando-se agora as estratégias por cenários sob a ótica dos clusters, para o cenário otimista, as estratégias que ficaram em evidência foram: "buscar empréstimos para expansão por meio de instituições financeiras nacionais" e "participar de fusão ou aquisição de IES". Este estudo contribui para melhor entender e compreender a importância dos cenários prospectados no ensino superior brasileiro, em especial no stricto sensu, trazendo como destaque algumas estratégias que, de acordo com diferentes finalidades, podem assessorar estes programas em suas respectivas perpetuidades e na criação de vantagem competitiva no mercado em que atuam no Brasil.

Palavras-chave: Programas de pós-graduação; Stricto sensu; Estratégias; Cenário otimista.

\section{PROBABLE STRATEGIES OF THE STRICTO SENSU PROGRAMS OF BRAZILAGAINST THE OPTIMISTIC SCENARIO PROSPECTED FROM 2019 TO 2030}

\section{Abstract}

The objective of this study was to identify the most likely strategies for the Stricto Sensu Programs of Higher Education Institutions in Brazil in the area of Public Administration and Business, Accounting and Tourism, against a optimistic scenario prospected for the period from 2019 to 2030, based on the methodology suggested by Blanning and Reinig (1998). Descriptive statistics and cluster analysis were also used, using cluster analysis. The basic results show that, in relation to the average use of strategies and the extreme use of strategies, the strategy "to promote the quality of theses and dissertations" was highlighted in the optimistic scenario. Focusing now on the scenarios strategies from the perspective of the clusters, the optimistic scenario was that the strategies that were in evidence were: "seek loans for expansion through national financial institutions" and "participate in mergers or acquisitions of HEIs." This study contributes to better understand and understand the importance of scenarios prospected in Brazilian higher education, especially in stricto sensu, highlighting some strategies that, according to different purposes, can advise these programs on their respective perpetuities and on the creation of competitive advantage in the market in which they operate in Brazil.

Keywords: Postgraduate programs; Stricto sensu; Strategies; Optimistic scenario.

1 - Universidade Federal do Piauí, Piauí, Brasil. 


\section{Introdução}

O exercício de construir cenários para diferentes setores de atuação pode ser um dos mais estratégicos aspectos para a sobrevivência e competitividade no mercado (Faller \& Almeida, 2014). Diante desse contexto, nota-se que o papel da educação é importante para prospectar cenários alternativos (Blass, Thornton \& Rawlings, 2011). Versa-se, assim, a importância de entender e compreender as condicionantes, tendências e a prospecção do cenário na educação (Thiesen, Garcez \& Guimaraes, 2014), sobretudo no ensino superior e mais especificamente na pós-graduação brasileira (Moritz et al., 2013).

Diante disso, a pesquisa de prospecção de cenários vem se tornando um instrumento valoroso para a educação superior (Rieckmann, 2012) nas IESs públicas e privadas do Brasil, pois contribui para a estratégia dos programas de pós-graduação, sobretudo para o planejamento estratégico (Lindgren \& Bandhold, 2003) alicerçado em uma investigação prospectiva de cenários/futuros prováveis/ preferidos (Hicks \& Gidley, 2012; Ithnin et al., 2018), sendo possível, assim, influenciar positivamente no clima organizacional, na mitigação de riscos (Godet, 2010), facilitando o processo decisórios (Oliveira \& Forte, 2009), as tomadas de decisões e as escolhas de estratégias competitivas (Porter, 1980) que, porventura, serão implementadas e adotadas (Sobreira et al., 2014).

Em relação à prospecção de cenários (Moritz et al., 2013) e às estratégias competitivas (Porter, 1980), surgem as capacidades dinâmicas e os recursos (Leite \& Porsse, 2003). Essas capacidades e os recursos são visualizados como elementos raros, de imitação e substituição complexa e trabalhosa no contexto das organizações (Barney, 1991). O conceito das capacidades e recursos inclui não apenas os tangíveis e econômicos/financeiros, mas, também, as capacidades e recursos in- tangíveis (Hall, 1992; Itami \& Roehl, 1987).

De maneira geral, entende-se que a Teoria das Capacidades Dinâmicas apresenta os pensamentos assentados nas teorias dos processos de mercado e na Teoria dos Recursos (Resource Based View - RBV), tendo em vista estabelecer uma teoria do desenvolvimento das competências organizacionais em cenários de alta complexidade, desempenho e transformação (Vasconcelos \& Cyrino, 2000). Em suma, o fenômeno das capacidades dinâmicas nas organizações compõe um ramo de enorme interesse para acadêmicos na área de administração, em diversos campos do conhecimento, desde gerenciamento estratégico, empreendedorismo, marketing, gestão de pessoas, gestão de operações, até o sistema de informação (Meirelles \& Camargo, 2014).

Sousa, Forte e Oliveira (2012) identificaram as dimensões de recursos estratégicos utilizadas pelas IES privadas da Região Nordeste para um cenário mais provável de ocorrência no período 2009/2015. Os resultados demonstram que o Cenário "Tudo pelo Mercado Adaptado" é o mais provável e que as IESs estão valorizando recursos que não proporcionam diferencial competitivo.

Moritz et al. (2013) concluíram, em sua pesquisa, que é esperado pela pós-graduação para 2020 no Brasil, que ela aja com uma consciência social alargada, atenta ao ambiente para aprendizagens expressivas e aos novos tempos da humanidade, em que pesquisa e trabalho são variáveis que não se excluem, e os que nela atuam necessitam utilizar de suas competências para achar opções de modificação a partir de práticas inovadoras nos mestrados e doutorados, cujas diferentes demandas começam a colocar-se no presente, seja de fato relevante para um renovado e inovador Brasil do futuro.

Heinzen e Marinho (2019) propuseram um modelo para alinhavar a formulação e implementação da estratégia em IES. Res- 
salta-se que, para a construção do modelo, foi utilizado a metodologia de cenário como input e considerados os principais elementos que possibilitam a formulação e implementação da estratégia. Os autores concluíram que a metodologia de cenário é um instrumento relevante para a gestão estratégica das IES.

Diante do exposto, e considerando o foco desta pesquisa, após ser realizado um levantamento da análise de cenários relacionados à área de educação, mas propriamente da pós-graduação, em especial do stricto sensu, constatou-se que poucos estudos investigaram a aplicação e o uso dos métodos de cenários no setor da educação superior (Heinzen, 2015).

Em vista disso, versa-se a seguir a questão de pesquisa que orientou e norteou este estudo que foi: Quais as estratégias mais prováveis pelos Programas de Stricto Sensu das IESs do Brasil da área de Administração Pública e de Empresas, Ciências Contábeis e Turismo frente ao cenário otimista prospectado para o período de 2019 a 2030 ? O objetivo geral foi identificar as estratégias mais prováveis pelos Programas de Stricto Sensu das IESs do Brasil da área de Administração Pública e de Empresas, Ciências Contábeis e Turismo frente ao cenário otimista prospectado para o período de 2019 a 2030. No que concerne ao estudo enfocar somente o cenário otimista, é explicado devido a este cenário em um determinado país manter atividades de pesquisa e desenvolvimento, cujas habilidades já foram legitimadas no passado (Scavarda \& Hamacher, 2001), contribuindo com isso para agregar valor científico no que tange ao objeto de pesquisa deste estudo que são os Programas de Pós-Graduação Stricto Sensu.

Justifica-se este estudo, pois, ao ressaltar que a importância do tema Cenário apareceu em razão de se ter observado que investigações sobre prospecção de cenários terem sido realizadas em diferentes países, e o Bra- sil está entre eles, relacionando o citado tema com setores de atividade, como por exemplo, setores: financeiro (Oliveira \& Forte, 2009), combustível (Silva et al., 2013), ensino superior (Sousa, Forte \& Oliveira, 2012; Spada \& Forte, 2018), turismo (Sobreira et al., 2014), construção civil (Silva \& Forte 2016). Diante do exposto, surge a possibilidade de unir o estudo de cenários com o ensino dos Programas de Stricto Sensu das IESs públicas e particulares do Brasil.

Versa que a pós-graduação stricto sensu apresenta-se como uma necessária fonte de criação de conhecimento para atender às emergentes demandas das empresas e da sociedade, então a escolha de se estudar o setor de ensino superior (Rieckmann, 2012), em destaque os Programas de Stricto Sensu das IES públicas e particulares do Brasil, se deve à relevância que este setor tem para o Brasil (Gaspar \& Campos, 2015; Maccari, Riccio \& Martins, 2013), sobretudo na área de Administração Pública e de Empresas, Ciências Contábeis e Turismo.

Em suma, pretende-se, assim, com esta pesquisa, oferecer uma contribuição para o Brasil chegar, o mais perto possível, dos cenários desejados (Polesi, 2006), para os Programas Stricto Sensu das IESs públicas e privadas da área de Administração Pública e de Empresas, Ciências Contábeis e Turismo. Como consequência disso cabe proporcionar, a posteriori, ao Brasil um futuro economicamente dinâmico, socialmente justo, regulado por um regime democrático eficaz e substantivo e com inserção internacional coerente em especial na área de educação (Polesi, 2006).

\section{Cenários, estratégia e pós-graduação}

Pode-se entender que a estratégia de cenários tem um efeito positivo na qualidade da tomada de decisão mais do que as ferramentas tradicionalmente usadas no planejamento estratégico, ou seja, as ferramentas de estraté- 
gia, tal como o planejamento de cenários, que têm efeitos cognitivos positivos, e que são amplamente reivindicadas na literatura acadêmica internacional, podem, de fato, fomentar a qualidade das decisões tomadas pelos gestores (Meissner \& Wulf, 2013).

Aplicar técnicas de planejamento de cenários é uma das abordagens mais tradicionais para o desenvolvimento de estratégias (O’Brien \& Meadows, 2013), pois ajuda as empresas a lidar com o gerenciamento das incertezas futuras (Blanning \& Reinig, 1998; Hirsch, Burggraf \& Daheim, 2013) e as mudanças evolutivas em seu ambiente circundante. Avaliar se este ambiente fornece insight (Blanning \& Reinig, 1998) sobre as mudanças únicas, além do que as implicações dessas mudanças têm sobre as estratégias de uma empresa, e a criação de técnicas especiais necessárias para compreendê-los. Com isso, entende-se e compreende-se que uma dessas técnicas especiais é o planejamento de prospecção de cenários (Walsh, 2005).

Diante disso, versa-se que o trabalho de arquitetar cenários para setores díspares de atuação é um dos mais estratégicos aspectos para a perpetuidade e para a criação de vantagem competitiva no mercado (Faller \& Almeida, 2014). Neste sentido, verifica-se que o papel da educação é ímpar para prospectar cenários (Blass, Thornton \& Rawlings, 2011). Ressalta-se, assim, a necessidade de entender e compreender as condicionantes, disposições e a estratégia do cenário na educação (Thiesen, Garcez \& Guimaraes, 2014), no ensino superior (Porto \& Régnier, 2003), em especial no contexto da pós-graduação brasileira (Moritz et al., 2013).

As IES's podem, devem e precisam utilizar a metodologia de cenários, pois esta protege essas instituições por meio da identificação de suas principais variáveis sociais, econômicas e estratégicas, vislumbrando seus prováveis futuros (Moritz et al., 2013), prepa- rando-as, com isso, para as diferentes possibilidades e probabilidades (Goodwin \& Wright, 2001) de ocorrências futuras (Moritz, Nuner \& Pereira, 2008), dando-lhes condições para um processo decisório (Morais, Forte \& Oliveira, 2015) e, consequentemente, para decisões mais estratégicas e proativas (Godet, 2010), com maior eficácia e, por conseguinte, tornando-as capazes à formulação de estratégias competitivas (Lindgren \& Bandhold, 2003), harmônicas e com a imprescindível visão de futuro (Silva et al., 2013).

Porém, diante da rapidez das mudanças, a adoção de posturas estratégicas como forma de sustentar a competitividade estratégica tem sido uma contingência imposta pelo ambiente interno e externo (Santos \& Cândido, 2013). É importante ressalvar que a Matriz SWOT busca consolidar aspectos que possam ser importantes para o negócio (Oliveira \& Forte, 2014), agrupando os pontos fortes e fracos do ambiente interno, bem como as oportunidades e ameaças do ambiente externo (Gonçalves, 2011). Diante do exposto, a organização pode escolher entre as seguintes posturas estratégicas: sobrevivência, manutenção, crescimento e desenvolvimento que são oriundas da Análise SWOT (Azevedo \& Costa, 2010; Oliveira et al., 2017; Sousa, Forte \& Oliveira, 2012).

É importante salientar que o objetivo da SWOT é definir estratégias para manter pontos fortes, minimizar a intensidade de pontos fracos, aproveitando oportunidades e protegendo-se de possíveis ameaças. Diante da ênfase de pontos fortes ou fracos e de oportunidades e ameaças, pode-se formular, implementar e adotar estratégias que busquem a sobrevivência, manutenção, crescimento ou desenvolvimento da empresa (Azevedo \& Costa, 2010). Isto posto, as referidas posturas serão colocadas em ênfase para se verificar a postura estratégica dos programas de pós-graduação stricto sensu e, a posteriori, observar a existência de relação entre tais posturas e suas 
respectivas estratégias competitivas no cenário otimista prospectado neste estudo.

\section{Procedimentos metodológicos}

Com o objetivo de identificar as estratégias mais prováveis pelos Programas de Stricto Sensu das IESs do Brasil da área de Administração Pública e de Empresas, Ciências Contábeis e Turismo frente ao cenário otimista prospectado para o período de 2019 a 2030, este estudo prospectou os pareceres de gestores dos Programas de Stricto Sensu, embasada pela metodologia sugerida por Blanning e Reinig (1998).

O universo deste estudo foram os Programas Stricto Sensu das Instituições de Ensino Superior Públicas e Privadas do Brasil da Área de Administração Pública e de Empresas, Ciências Contábeis e Turismo. Em razão de este universo contribuir para o aperfeiçoamento de cursos de doutorado e mestrado por meio do trabalho científico (Maccari et al., 2009), e se verificar que a pós-graduação stricto sensu é um sucesso em termos de nações emergente (Bertero, Caldas \& Wood Jr, 1999), justifica-se, as- sim, focar este estudo neste universo de pesquisa.

Em vista disso, evidenciam-se que os Programas Stricto Sensu das Instituições de Ensino Superior Públicas e Privadas do Brasil da Área de Administração Pública e de Empresas, Ciências Contábeis e Turismo existentes e associados à Associação Nacional de Pós-Graduação e Pesquisa em Administração (ANPAD) fizeram parte do universo de estudo desta pesquisa. Neste contexto, versa-se que a amostra dos Programas Stricto Sensu das Instituições de Ensino Superior Públicas e Privadas do Brasil da Área de Administração para se realizar este estudo foi feita por acessibilidade. A amostra foi composta pelos Programas Associados a ANPAD, composto por 126 programas.

$\mathrm{Na}$ primeira etapa de coleta de dados da referida pesquisa foram entrevistados cinco peritos (Figura 1), todos doutores e vinculados a programas de pós-graduação stricto sensu da área de Administração Pública e de Empresas, Ciências Contábeis e Turismo. Os mesmos foram selecionados mediante acessibilidade.

\begin{tabular}{|c|c|c|}
\hline Peritos & Organização & Curso/Programa \\
\hline Entrevistado 1 & $\begin{array}{c}\text { Universidade Nove de } \\
\text { Julho/UNINOVE }\end{array}$ & $\begin{array}{c}\text { Programa de Mestrado Profissional em Administração } \\
\text { - Gestão Ambiental e Sustentabilidade/PMPA-GeAS }\end{array}$ \\
\hline Entrevistado 2 & $\begin{array}{c}\text { Escola Superior de Propaganda e } \\
\text { Marketing de São Paulo/ESPM }\end{array}$ & $\begin{array}{c}\text { Doutorado e Mestrado em Administração } \\
\text { Programa de Mestrado e Doutorado em Administração } \\
\text { em Gestão Internacional/PMDGI }\end{array}$ \\
\hline Entrevistado 3 & $\begin{array}{c}\text { Centro Universitário das } \\
\text { Faculdades Metropolitanas } \\
\text { Unidas/FMU }\end{array}$ & $\begin{array}{c}\text { Professor do Centro Universitário das Faculdades } \\
\text { Metropolitanas Unidas/FMU }\end{array}$ \\
\hline Entrevistado 4 & $\begin{array}{c}\text { Faculdade de Economia, } \\
\text { Administração e } \\
\text { Contabilidade/FEA } \\
\text { Universidade de São Paulo/USP }\end{array}$ & Mestrado Profissional em Empreendedorismo/MPE \\
& $\begin{array}{c}\text { Faculdade de Economia, } \\
\text { Administração e } \\
\text { Contabilidade/FEA } \\
\text { Universidade de São Paulo/USP }\end{array}$ & Professor Titular da Faculdade de Economia, \\
& \multicolumn{2}{|c|}{\begin{tabular}{c} 
Paulo (FEA-USP) \\
\hline
\end{tabular}}
\end{tabular}

Figura 1: Peritos entrevistados

Fonte: Elaborado pelos autores 
O contato inicial foi por meio de contato por e-mail. Uma carta de apresentação foi enviada, e o Roteiro das Entrevistas foi desenvolvido mediante uma extensa revisão da bibliografia (Maccari et al., 2009; Maccari, Lima \& Riccio, 2009; Maccari, Riccio \& Martins, 2013; Martins et al., 2013; Moritz et al., 2013; Moritz, Nuner \& Pereira, 2008; Rocha Neto, 2010; Sousa, Forte \& Oliveira, 2012).

Para a segunda etapa do estudo, que foi a construção da listagem dos eventos, para isso uma listagem dos eventos foi enviada, por meio de perguntas, utilizando uma survey a 35 especialistas, conseguindo uma devolutiva de 29 (Figura 2) para que indicassem a probabilidade de ocorrência destes eventos e o quão favorável e pertinentes estes serão caso ocorra em uma linha graduada de zero a dez.

Como critério de escalação dos peritos, foram considerados cargos de Direção e ou ser Docente/Pesquisador com Titulação de
Doutor(a) de IES Públicas e ou privadas existentes no Brasil da área de Administração Pública e de Empresas, Ciências Contábeis e Turismo. Realçam-se que os peritos escolhidos atendem ao requisito de entender e compreender os direcionamentos, políticas e ações desenvolvidas nos Programas de Stricto Sensu de IES públicas e ou privadas existentes no Brasil da área de Administração Pública e de Empresas, Ciências Contábeis e Turismo.

Versa-se que o convite aos especialistas aconteceu pelos seguintes meios de comunicação: e-mail, telefone, pessoalmente, após a confirmação do especialista no estudo da prospecção dos cenários. A seguir, aplicou-se o questionário de acordo com o método de sugerido por Blanning e Reinig (1998). Salienta-se que, no que tange à estrutura do questionário, foi embasado e norteado nos conceitos de pertinência (Marcial \& Grumbach, 2002) e de favorabilidade e probabilidade (Blanning \& Reinig, 1998).

\begin{tabular}{|c|c|c|c|}
\hline Peritos (P) & Titulação & Organização & Função \\
\hline P1 & Doutor(a) & Centro Universitário Maurício de Nassau & Diretor(a) \\
\hline $\mathrm{P} 2$ & Doutor(a) & Universidade Federal de Uberlândia & Docente/Pesquisador(a) \\
\hline P3 & Doutor(a) & Centro Universitário das Faculdades Metropolitanas Unidas & Docente/Pesquisador(a) \\
\hline P4 & Doutor(a) & Universidade Nove de Julho & Docente/Pesquisador(a) \\
\hline P5 & Doutor(a) & Universidade Nove de Julho & Docente/Pesquisador(a) \\
\hline P6 & Doutor(a) & Universidade Federal de Uberlândia & Docente/Pesquisador(a) \\
\hline P7 & Doutor(a) & Faculdade Anglo & Docente/Pesquisador(a) \\
\hline P8 & Doutor(a) & Universidade Nove de Julho & Docente/Pesquisador(a) \\
\hline P9 & Doutor(a) & Universidade Federal da Paraíba & Docente/Pesquisador(a) \\
\hline P10 & Doutor(a) & Universidade Federal da Grande Dourados & Docente/Pesquisador(a) \\
\hline P11 & Doutor(a) & Universidade de Taubaté & Docente/Pesquisador(a) \\
\hline P12 & Doutor(a) & Centro Universitário Maurício de Nassau & Diretor(a) \\
\hline P13 & Doutor(a) & Universidade Nove de Julho & Docente/Pesquisador(a) \\
\hline P14 & Doutor(a) & Centro Universitário Maurício de Nassau & Diretor(a) \\
\hline P15 & Doutor(a) & Universidade Nove de Julho & Docente/Pesquisador(a) \\
\hline P16 & Doutor(a) & Universidade Federal de Santa Catarina & Docente/Pesquisador(a) \\
\hline P17 & Doutor(a) & Universidade Federal do Triângulo Mineiro & Docente/Pesquisador(a) \\
\hline P18 & Doutor(a) & Universidade Federal do Piauí & Docente/Pesquisador(a) \\
\hline P19 & Doutor(a) & Universidade Federal de Mato Grosso & Docente/Pesquisador(a) \\
\hline P20 & Doutor(a) & Universidade Federal de Mato Grosso do Sul & Docente/Pesquisador(a) \\
\hline P21 & Doutor(a) & Universidade Nove de Julho & Docente/Pesquisador(a) \\
\hline P22 & Doutor(a) & Universidade do Vale do Rio dos Sinos & Docente/Pesquisador(a) \\
\hline P23 & Doutor(a) & Universidade Nove de Julho & Docente/Pesquisador(a) \\
\hline P24 & Doutor(a) & Centro Universitário Maurício de Nassau & Diretor(a) \\
\hline P25 & Doutor(a) & Centro Universitário Maurício de Nassau & Diretor(a) \\
\hline P26 & Doutor(a) & Universidade Federal do Piauí & Docente/Pesquisador(a) \\
\hline P27 & Doutor(a) & Centro Universitário da Fundação Educacional Inaciana & Docente/Pesquisador(a) \\
\hline P28 & Doutor(a) & Universidade Nove de Julho & Docente/Pesquisador(a) \\
\hline P29 & Doutor(a) & Centro Universitário Maurício de Nassau & Diretor(a) \\
\hline
\end{tabular}

\section{Figura 2: Peritos}

Fonte: Elaborado pelos autores 
Com isso, em relação à pertinência, os peritos aferiram em uma escala tipo Likert de zero a cinco, em que (zero = sem influência; um = muito pouca influência; dois = pouca influência; três = razoável influência; quatro = forte influência; e cinco = extrema influência). De maneira geral, os peritos focaram sobre a pertinência da ocorrência ou não de algum evento na construção dos cenários, sendo o critério pertinência (importância) livre da possibilidade de ocorrência deste evento ou não (Marcial \& Grumbach, 2002).

No que se refere à favorabilidade, versa sobre o quanto o evento é aderente para a construção dos cenários. Com isso, para esse critério, foi utilizada a escala de zero a $100 \%$, com intervalos de $10 \%$ em $10 \%$. Para o discernimento da perspectiva de ocorrência das variáveis na construção dos cenários, também foi utilizada a escala de zero a $100 \%$, com intervalos de 10\% em 10\% (Blanning \& Reinig, 1998). Justifica-se que a escolha pela escala do tipo Likert se deve às seguintes vantagens de ser fácil para o pesquisador construí-la e aplicá-la, assim como é simplificada para o respondente entendê-la e compreendê-la, tor- nando aceitável o breve retorno do respondente.

Logo em seguida foi realizada a construção de uma matriz de eventos, colocando no eixo horizontal as expectativas de ocorrência destes eventos (P) e, no eixo vertical, o quanto cada evento é apto ou contrário (F) para as IES's que estão sendo desenvolvidas as análises. Por último, a Figura 3 mostra a construção de três cenários: (i) cenário otimista; (ii) cenário pessimista; e (iii) cenário realista (Blanning \& Reinig, 1998), porém, para este estudo, enfocou-se o Cenário Otimista.

O processo de filtragem dos eventos foi feito por meio das seguintes ações: (i) cinco especialistas indicaram admissíveis e possíveis eventos; (ii) busca na literatura científica destes eventos (Maccari et al., 2009; Maccari, Lima \& Riccio, 2009; Maccari, Riccio \& Martins, 2013; Martins et al., 2013; Moritz et al., 2013; Moritz, Nuner \& Pereira, 2008; Rocha Neto, 2010; Sousa, Forte \& Oliveira, 2012). Foi feito uma consolidação desses eventos, evitando assim duplicidade e ou redundância destes, surgindo com isso os eventos evidenciados na Tabela 1. 
Tabela 1: Eventos

\begin{tabular}{|c|c|c|c|}
\hline Eventos & $\begin{array}{l}\text { Perti } \\
\text { nênc } \\
\text { ia }\end{array}$ & $\begin{array}{l}\text { Favor } \\
\text { abilid } \\
\text { ade }\end{array}$ & $\begin{array}{l}\text { Proba } \\
\text { bilida } \\
\text { de }\end{array}$ \\
\hline $\begin{array}{l}\text { V3 - O programa procura manter as notas de excelência da Coordenação de Aperfeiçoamento } \\
\text { de Pessoal de Nível Superior (CAPES) }\end{array}$ & $14 \%$ & $\begin{array}{r}80,53 \\
\% \\
\end{array}$ & $\begin{array}{r}77,37 \\
\% \\
\end{array}$ \\
\hline $\begin{array}{l}\text { V6 - O programa incentiva a participação dos docentes em grupos de pesquisa, convênios e } \\
\text { intercâmbios com universidades e centros de pesquisa do exterior universidades e centros } \\
\text { de pesquisa do exterior }\end{array}$ & $17 \%$ & $\begin{array}{r}80,00 \\
\%\end{array}$ & $\begin{array}{r}66,32 \\
\% \\
\end{array}$ \\
\hline V4 - O programa incentiva a publicação em periódicos internacionais como fator de impacto & $15 \%$ & $\begin{array}{r}80,00 \\
\%\end{array}$ & $\begin{array}{r}73,68 \\
\%\end{array}$ \\
\hline $\begin{array}{l}\text { V9 - Corpo docente de alta performance na produção acadêmica e relevância internacional é } \\
\text { recurso estratégico }\end{array}$ & $19 \%$ & $\begin{array}{r}78,95 \\
\% \\
\end{array}$ & $\begin{array}{r}72,11 \\
\% \\
\end{array}$ \\
\hline $\begin{array}{l}\text { V2 - Recursos estratégicos criam vantagem competitiva sustentável no programa de pós- } \\
\text { graduação stricto sensu }\end{array}$ & $14 \%$ & $\begin{array}{r}76,84 \\
\% \\
\end{array}$ & $\begin{array}{r}67,89 \\
\% \\
\end{array}$ \\
\hline $\begin{array}{l}\text { V8 - Grupos e projetos de pesquisa são formados para fortalecer a publicação científica, bem } \\
\text { como parcerias internacionais }\end{array}$ & $18 \%$ & $\begin{array}{r}76,32 \\
\% \\
\end{array}$ & $\begin{array}{r}70,00 \\
\% \\
\end{array}$ \\
\hline estratégicos são essenciais para qualidade no programa de pós-graduação & $13 \%$ & $\begin{array}{r}75,26 \\
\% \\
\end{array}$ & $\begin{array}{r}68,95 \\
\% \\
\end{array}$ \\
\hline $\begin{array}{l}\text { V11 - A presença de renomados professores internacionais em eventos, palestras, cursos, e } \\
\text { "summer courses", incentivam a internacionalização do programa }\end{array}$ & $20 \%$ & $\begin{array}{r}74,21 \\
\% \\
\end{array}$ & $\begin{array}{r}66,84 \\
\% \\
\end{array}$ \\
\hline $\begin{array}{l}\text { V13 - O programa incentiva com recursos a participação de docentes e discente em eventos } \\
\text { internacionais }\end{array}$ & $20 \%$ & $\begin{array}{r}73,16 \\
\% \\
\end{array}$ & $\begin{array}{r}64,21 \\
\% \\
\end{array}$ \\
\hline $\begin{array}{l}\text { V5 - Recursos estratégicos impactam na formação de pesquisadores e contribuem no } \\
\text { desenvolvimento de suas atividades }\end{array}$ & $16 \%$ & $\begin{array}{r}73,16 \\
\% \\
\end{array}$ & $\begin{array}{r}66,32 \\
\% \\
\end{array}$ \\
\hline $\begin{array}{l}\text { V7 - Recursos estratégicos são preponderantes para incentivar a internacionalização do } \\
\text { programa de pós-graduação stricto sensu }\end{array}$ & $18 \%$ & $\begin{array}{r}72,63 \\
\% \\
\end{array}$ & $\begin{array}{r}63,16 \\
\% \\
\end{array}$ \\
\hline V14 - O programa integra docentes de outras IESs para desenvolver pesquisas conjuntas & $20 \%$ & $\begin{array}{r}72,11 \\
\% \\
\end{array}$ & $\begin{array}{r}71,58 \\
\% \\
\end{array}$ \\
\hline $\begin{array}{l}\text { V12 - O processo seletivo estimula participação de candidatos, com base no mérito e } \\
\text { desempenho acadêmico }\end{array}$ & $20 \%$ & $\begin{array}{r}68,95 \\
\% \\
\end{array}$ & $\begin{array}{r}66,84 \\
\% \\
\end{array}$ \\
\hline $\begin{array}{l}\text { V10 - O programa de pós-graduação stricto sensu influencia na atuação de egressos em } \\
\text { programas de stricto sensu de diferentes regiões }\end{array}$ & $19 \%$ & $\begin{array}{r}66,32 \\
\%\end{array}$ & $\begin{array}{r}66,32 \\
\% \\
\end{array}$ \\
\hline
\end{tabular}

Fonte: Dados da pesquisa

De maneira geral, a Figura 3 contempla a construção dos três cenários deste estudo: (i) cenário otimista; (ii) cenário pessimista; e (iii) cenário realista (Blanning \& Reinig,
1998). Porém, de acordo com a questão e o objetivo propostos neste estudo, o mesmo enfatizará apenas a prospecção do cenário otimista. 


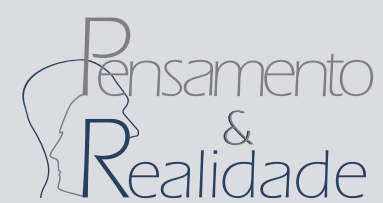

Figura 3: Cenários: otimista, realista e pessimista

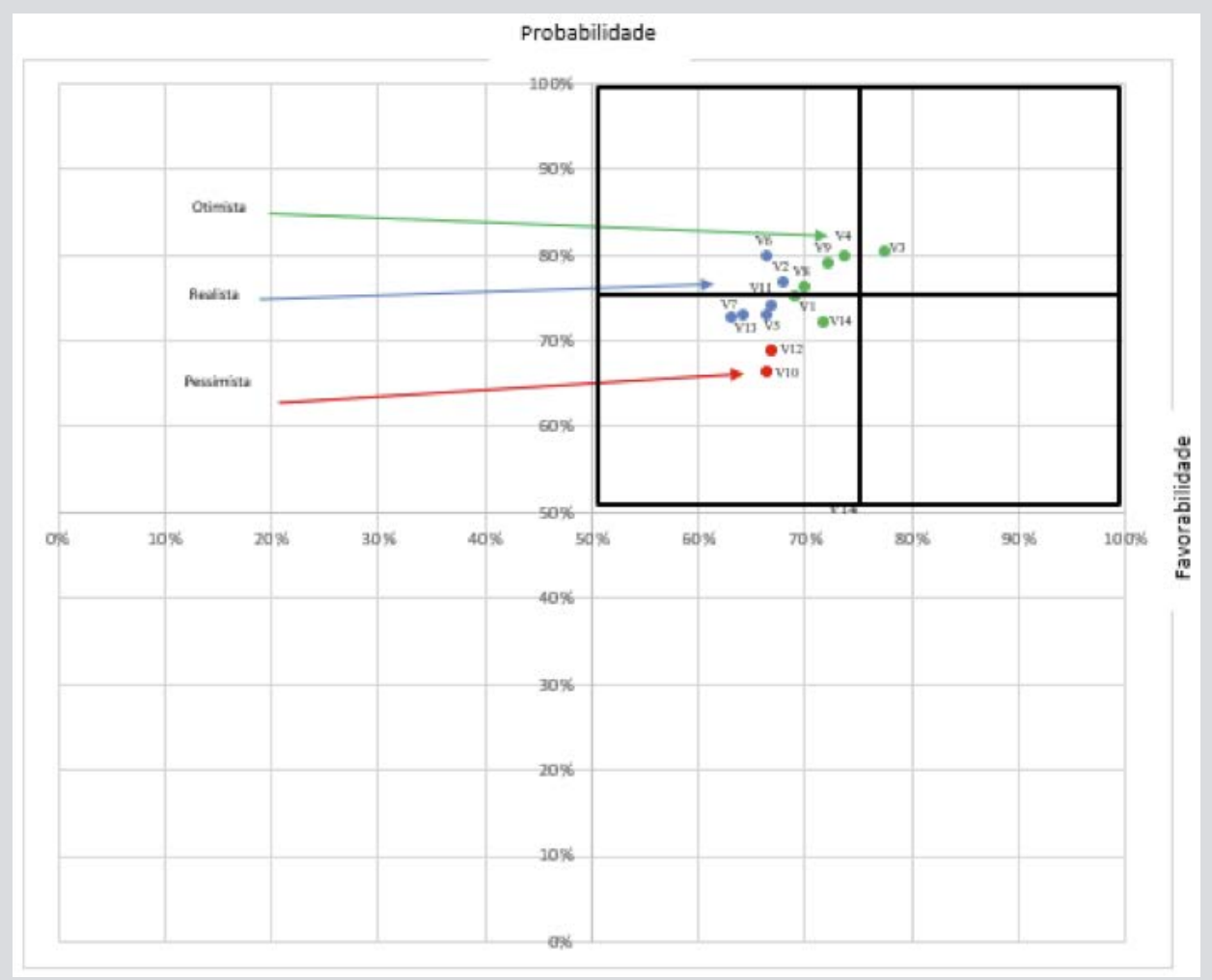

Fonte: Dados da pesquisa

No que tange ao filtro de Pertinência, sua aferição foi alcançada por meio das seguintes etapas: (i) foi tirada a média pegando por base as respostas de Pertinência dos 29 peritos; (ii) foi calculado o desvio-padrão, também pegando por base as respostas de Pertinência dos 29 peritos; e (iii) foi mensurado o coeficiente de variação, por meio da divisão entre o desvio-padrão com a média.

Para se conseguir responder e alcançar a questão e o objetivo do estudo, os dados foram coletados mediante uma survey online, hospedada na plataforma Survey Monkey e distribuída por diversas mídias para o público-alvo. A survey foi conduzida de forma que o respondente deliberadamente respondia ao questionário. Ao todo, 41 respondentes formaram a amostra dos dados. Este estudo utilizou técnicas estatísticas, tais como estatística descritiva e análise de agrupamento, além de abordar técnicas de redução, pertencentes ao grupo de técnicas multivariadas de interdependência (Maroco, 2014).
O tamanho da amostra pode influenciar diretamente nas estimativas dos parâmetros calculados (Rao, 2013). Portanto, em cada procedimento estatístico, o pressuposto da amostra mínima foi avaliado, indicando a tendência de enviesar as medidas calculadas. Para não ser restringido no uso de procedimentos mais avançados, a técnica de reamostragem foi utilizada, com o objetivo de aumentar o tamanho da amostra artificialmente, mantendo o padrão das respostas originais. A reamostragem ou bootstrap utilizou 300 reamostragens buscando a aproximação dos dados da distribuição normal. Os procedimentos estatísticos adotados foram realizados no ambiente de software SPSS v. 023 e no Excel 2016.

Ao todo, 47 estratégias (Figura 4) foram submetidas à avaliação dos respondentes, cada uma sendo avaliada no cenário otimista. As estratégias foram redigidas sob afirmações e avaliadas em uma escala likert de zero a cinco. Ressaltam-se que as citadas estratégias 
foram elencadas e organizadas por meio das suas respectivas posturas mediante uma revisão da literatura, utilizando estudos, sobretudo, de artigos publicados em revistas científicas (Maccari et al., 2009; Maccari, Lima \& Riccio, 2009; Maccari, Riccio \& Martins, 2013; Martins et al., 2013; Moritz et al., 2013; Moritz, Nuner \& Pereira, 2008; Rocha Neto, 2010; Sousa, Forte \& Oliveira, 2012).

Para fins descritivos, as estratégias avaliadas foram categorizadas em cenários. Algumas medidas foram utilizadas para sumarizá-las com a média, sendo a medida de tendência central, o desvio-padrão (S.D), como medida de variabilidade e, o coeficiente de variação, sendo também uma medida de variabilidade, porém, com melhor interpretabilidade do que o desvio- padrão. O coeficiente de variação pode ser interpretado como uma porcentagem, que indica se a variabilidade é alta em determinada variável. Sendo alta, a mediana passa a ser uma medida mais confiável do que a média para sumarizar os resultados. Maroco (2014) indica que até 0,3, a taxa de variabilidade não é considerada alta. Após a análise descritiva dos dados, indicando quais as estratégias mais prováveis de serem utilizadas no cenário otimista, foi utilizada a análise de conglomerados ou análise de cluster para identificar, por exemplo, quais estratégias se diferem mais de cenário para cenário. Algumas estratégias que podem não ter obtido médias altas nos cenários, podem ser estratégias chave para delimitar um plano de ação em determinado cenário. Aquelas estratégias que melhor conseguem discriminar os cenários, tendem a ser escolhidas junto às estratégias já cotadas pela maioria. 


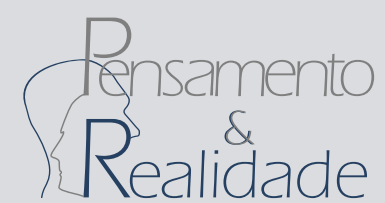

\begin{tabular}{|c|c|}
\hline Posturas & Estratégias \\
\hline$\frac{\frac{\pi}{2}}{\frac{y}{9}}$ & 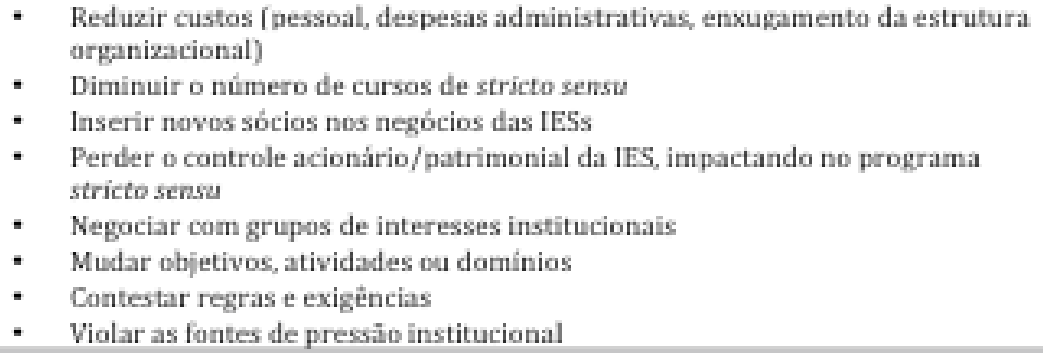 \\
\hline 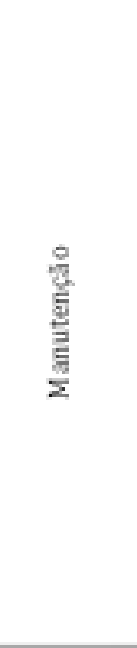 & 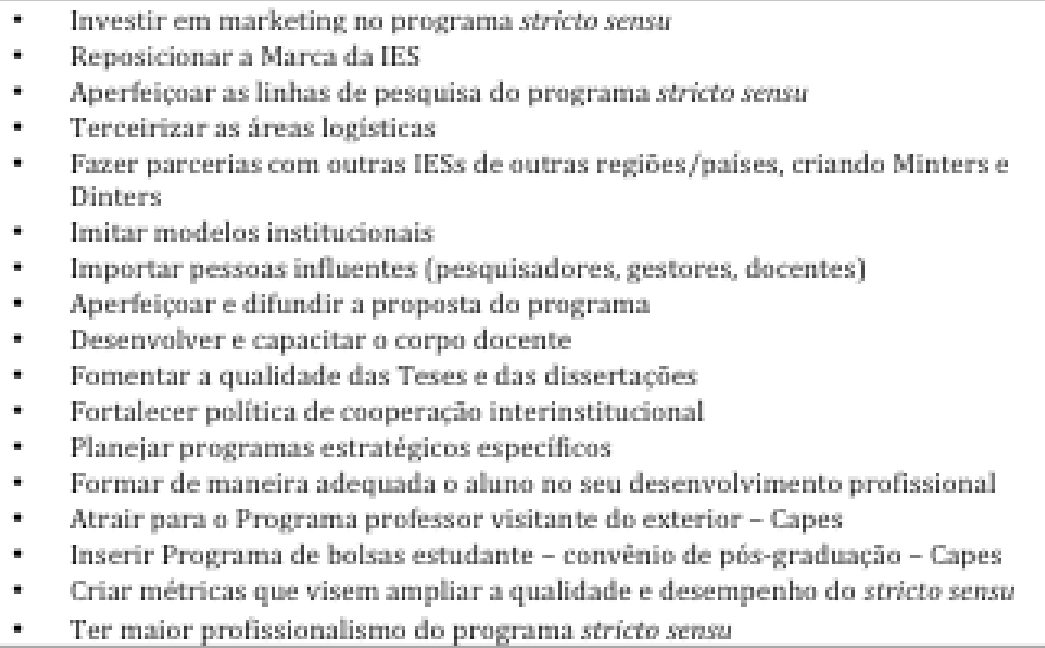 \\
\hline 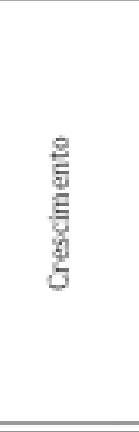 & $\begin{array}{l}\text { - Lançar nowos cursos de stricto sensu em outras áreas análogas a } \\
\text { administraçî́o, contabilidade e ou turismo } \\
\text { - Expandir o Campus em Unidades fora da Sede fno mesmo municipio ou no } \\
\text { interior] } \\
\text { - Aumentar o número de cursos de stricto sensu } \\
\text { - Implantar unidades em outros Estados do Brasil } \\
\text { - Implementar programas de Qualidade com Certificação } \\
\text { - } \quad \text { Buscar empréstimos para expansão por meio de instituiçōes financeiras } \\
\text { - } \quad \text { Participar de fusiio ou aquisição de IES } \\
\text { - Capacitar o universo docente em regiōes menos favorecidas } \\
\text { - Incorporar necessidades e desafios, em particular, em cada região do pais }\end{array}$ \\
\hline 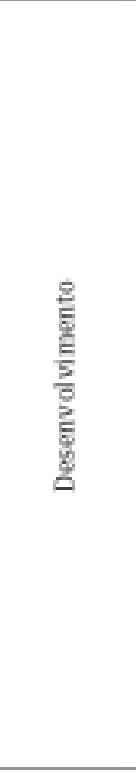 & 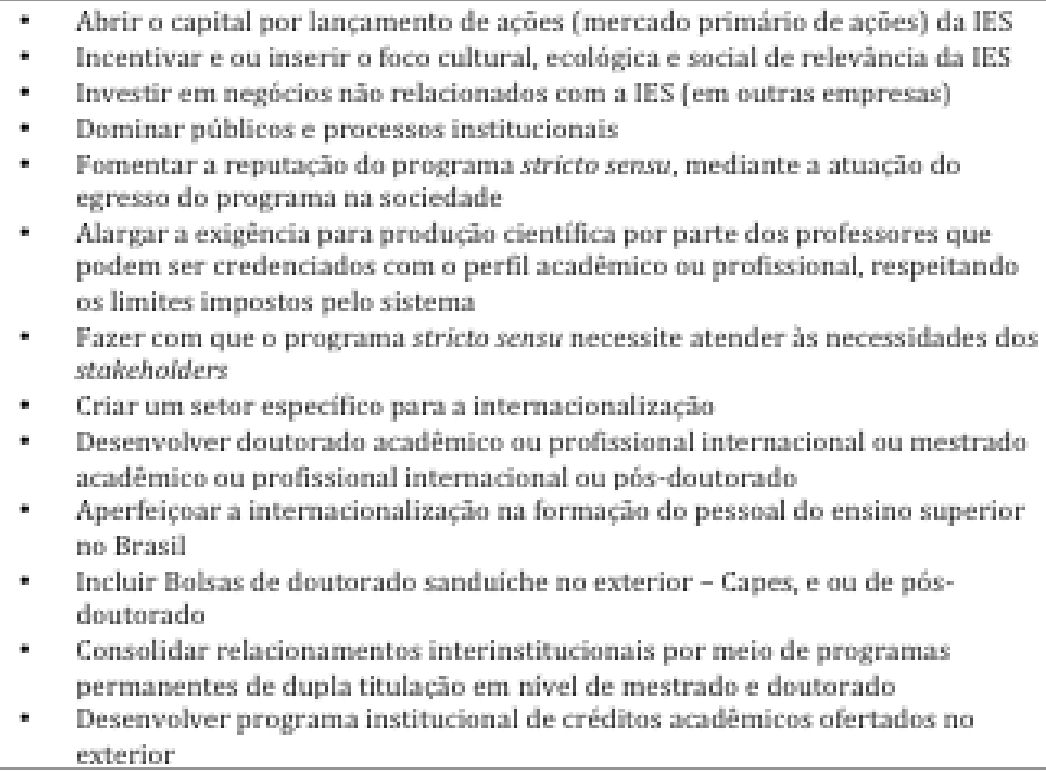 \\
\hline
\end{tabular}

Figura 4: Posturas e estratégias

Fonte: Elaborado pelos autores 
A análise de cluster consiste na classificação de objetos (casos ou variáveis), de modo que cada objeto semelhante a outro, vai sendo agrupado em um conglomerado. A semelhança é verificada por meio de uma medida de distância, cujo estrada são as características avaliadas para aqueles objetos (Maroco, 2014). A análise foi conduzida em duas etapas, a constar: cluster hierárquico e cluster não hierárquico (k-means). Foram criados os dendogramas dos clusters hierárquicos dos grupos e das estratégias que são apresentados nas Figuras 5 e 6 respectivamente. Foi estabelecido um ranking de estratégias no cenário otimista. O teste ANOVA verifica se as médias entre os clusters são significativamente diferentes. Além disso, pela medida do teste $\mathrm{Z}$ ou teste $\mathrm{F}$ de ANOVA, foi possível informar quais estratégias melhor diferenciam os grupos no cenário otimista

\section{Análise e discussão dos resultados \\ Esta seção aborda a análise e a discus-} são dos resultados.

\subsection{Utilização das estratégias no cenário otimista}

A Tabela 2 evidencia as 10 maiores médias na escala de utilização no cenário otimista e consta os resultados descritivos das estratégias que obtiveram as maiores médias no cenário otimista, em uma escala de zero a cinco. A estratégia com maior média foi "Fortalecer política de cooperação interinstitucional". Tal variável reflete a preocupação dos respondentes, no cenário otimista, para o fomento dos programas stricto sensu ora analisados com eventos estratégicos específicos para capacitação do universo docente (Cirani, Silva \& Campanario, 2015).

Isto posto, enfatiza-se que, ao longo das últimas décadas, o foco da pós-graduação nacional foi, essencialmente, a formação de docentes e pesquisadores para as próprias IESs e para o próprio sistema acadêmico brasileiro, contudo, tal foco precisa estar atento às mudanças nas demandas da sociedade, contribuindo para o avanço do conhecimento, e, consequentemente, colaborando para o fomento da formação destes profissionais para as instituições de ensino superior e para o meio científico-acadêmico de outras regiões do país, impactando no desenvolvimento social e econômico (Capes, 2018). 
Tabela 2: As 10 maiores médias na escala de utilização - cenário otimista

\begin{tabular}{|c|c|c|c|c|}
\hline Estratégias & Posturas & Média & S.D & CV \\
\hline $\begin{array}{l}\text { Fortalecer } \\
\text { política de } \\
\text { cooperação } \\
\text { interinstitucion } \\
\text { al }\end{array}$ & Manutenção & 4,27 & 0,74 & 0,17 \\
\hline $\begin{array}{l}\text { Fomentar a } \\
\text { qualidade das } \\
\text { Teses e das } \\
\text { dissertações }\end{array}$ & Manutenção & 4,20 & 0,90 & 0,21 \\
\hline $\begin{array}{l}\text { Ter maior } \\
\text { profissionalism } \\
\text { o do programa } \\
\text { stricto sensu }\end{array}$ & Manutenção & 4,15 & 0,73 & 0,18 \\
\hline $\begin{array}{l}\text { Criar métricas } \\
\text { que visem } \\
\text { ampliar a } \\
\text { qualidade e } \\
\text { desempenho } \\
\text { do stricto sensu }\end{array}$ & Manutenção & 4,10 & 0,77 & 0,19 \\
\hline $\begin{array}{l}\text { Criar um setor } \\
\text { específico para } \\
\text { a } \\
\text { internacionaliz } \\
\text { ação }\end{array}$ & $\begin{array}{l}\text { Desenvolvimen } \\
\text { to }\end{array}$ & 4,10 & 0,74 & 0,18 \\
\hline $\begin{array}{l}\text { Formar, de } \\
\text { maneira } \\
\text { adequada, o } \\
\text { aluno no seu } \\
\text { desenvolvimen } \\
\text { to profissional }\end{array}$ & Manutenção & 4,07 & 0,69 & 0,17 \\
\hline $\begin{array}{l}\text { Atrair para o } \\
\text { Programa } \\
\text { professor } \\
\text { visitante do } \\
\text { exterior - } \\
\text { Capes }\end{array}$ & Manutenção & 4,07 & 0,98 & 0,24 \\
\hline $\begin{array}{l}\text { Fazer parcerias } \\
\text { com outras } \\
\text { IESs de outras } \\
\text { regiões/países, } \\
\text { criando } \\
\text { Minters e } \\
\text { Dinters } \\
\end{array}$ & Manutenção & 4,00 & 1,02 & 0,26 \\
\hline $\begin{array}{l}\text { Desenvolver e } \\
\text { capacitar o } \\
\text { corpo docente }\end{array}$ & Manutenção & 4,00 & 1,12 & 0,28 \\
\hline $\begin{array}{l}\text { Inserir } \\
\text { Programa de } \\
\text { bolsas } \\
\text { estudante - } \\
\text { convênio de } \\
\text { pós-graduação }\end{array}$ & Manutenção & 3,98 & 1,17 & 0,29 \\
\hline
\end{tabular}

Fonte: Dados da pesquisa 
Em seguida, surgem as estratégias: (a) Fomentar a qualidade das teses e das dissertações; (b) Ter maior profissionalismo do programa stricto sensu; (c) Criar métricas que visem ampliar a qualidade e o desempenho do stricto sensu; (d) Criar um setor específico para a internacionalização; (e) Formar de maneira adequada o aluno no seu desenvolvimento profissional; (f) Atrair para o Programa professor visitante do exterior - Capes; (g) Fazer parcerias com outras IESs de outras regiões/países, criando Minters e Dinters; (h) Desenvolver e capacitar o corpo docente; e (i) Inserir Programa de bolsas estudante - convênio de pós-graduação.

De certa forma, os programas stricto sensu, no cenário otimista, ao se preocuparem com o desenvolvimento e capacitação do corpo docente (Moritz et al., 2013), que é um dos critérios para se avaliar e atribuir um conceito para o programa de pós-graduação (Capes, 2016), tende a influenciar na qualidade das teses e das dissertações, deixando claro o maior profissionalismo destes programas, possibilitando a ampliação da qualidade e desempenho (Maccari et al., 2009).

Isso faz com que estes programas possam atrair professores visitante do exterior, contemplando, assim, de certa maneira, as nuances da internacionalização (Moritz et al., 2013), que é foco, de muitos programas de stricto sensu, fazendo com que possam surgir parcerias com outras IESs de outras regiões/ países (Moritz et al., 2013), criando Minters e Dinters, gerando valor e ajudando com isso a formar, de maneira adequada, o aluno no seu desenvolvimento profissional, por meio de bolsas de pós-graduação, fortalecendo a política de cooperação interinstitucional destes programas, sobretudo, em regiões menos favorecidas (Cirani, Campanario \& Silva, 2015).

\subsection{Estratégias com extrema utilização no}

\section{cenário otimista}

A Tabela 3 contempla as 10 maiores estratégias com extrema utilização no cenário otimista. Percebe-se que há um maior equilíbrio entre os pontos da escala. $\mathrm{Na} \mathrm{Ta-}$ bela 3 , o fomento à qualidade das teses e das dissertações foi uma estratégia que recebeu o maior número de pontos máximos da escala, revelando que os respondentes, em um cenário otimista, julgam que é importante implementar esta estratégia.

Importante ressaltar que, ao fomentar a qualidade das dissertações e ou teses dos programas stricto sensu ora analisados, estes, no cenário otimista, transparece a seriedade, envergadura e robustez das linhas de pesquisa que alicerçam os respectivos programas, impactando diretamente, a posteriori, em publicações que serão divulgadas em meios de comunicação (eventos e ou revistas científicas de com alto fator de impacto), contribuindo para que esses programas evoluam na vitrine do mercado acadêmico nacional (Sousa, Forte \& Oliveira, 2012) e quiçá internacional.

Aqui é importante salientar que a produção científica internacional aumentou e melhorou nos últimos anos. Tal constatação e resultado são creditados em razão das transformações de critérios de valorização da produção acadêmica da área em análise a partir do Triênio 2007-2009 e que foi anunciada em 2005. Com isso, deixou-se de valorar a produção em congressos para prestigiar apenas artigos em periódicos científicos, sobretudo de bom fator de impacto (Capes, 2016). Reitera-se, assim, a importância de potencializar e estimar a produção científica nos programas de pós-graduação, como estratégia competitiva (Heinzen \& Marinho, 2018), em diferentes cenários alternativos (Goodwin \& Wright, 2001; Blass, Thornton \& Rawlings, 2011).

Não obstante, as maiores médias convergem com os itens de maior frequência na escala máxima. As outras estratégias que se 
destacaram nesta seção da pesquisa foram: (a) Fortalecer política de cooperação interinstitucional; (b) Inserir programa de bolsas estudante - convênio de pós-graduação - Capes;

(c) Desenvolver e capacitar o corpo docente;

(d) Incluir bolsas de doutorado sanduíche no exterior - Capes, e ou de pós-doutorado; (e) Atrair para o programa professor visitante do exterior - Capes; (f) Criar métricas que visem ampliar a qualidade e desempenho do stricto sensu; (g) Ter maior profissionalismo do programa stricto sensu; (h) Criar um setor específico para a internacionalização; e (i) Fazer parcerias com outras IESs de outras regiões/ países, criando Minters e Dinters.
Quando é enfatizada a estratégia "Desenvolver e capacitar o corpo docente", esta também está atrelada a um dos objetivos principais de um curso de pós-graduação stricto sensu que é formar mestres e doutores (Capes, 2018), com isso, tal fato incorre na formação dos docentes / pesquisador, dando a eles habilidades e competências (Moritz et al., 2013) capazes de lhes transformar em profissionais com maior conhecimento científico em suas respectivas área do saber, contribuindo para uma independência científica e intelectual, colaborando para o progresso científico, tecnológico, econômico e social do Brasil (Capes, 2018). 


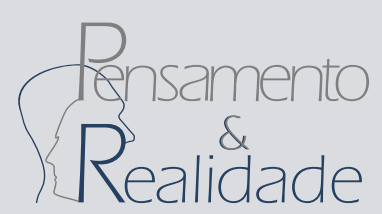

Tabela 3: Cenário otimista: as 10 maiores em extrema utilização

\begin{tabular}{|c|c|c|c|c|c|c|c|}
\hline $\begin{array}{c}\text { Estratégia } \\
\mathrm{s}\end{array}$ & Posturas & $\begin{array}{c}\text { Sem } \\
\text { utilização }\end{array}$ & $\begin{array}{c}\text { Muito } \\
\text { pouca } \\
\text { utilização }\end{array}$ & $\begin{array}{c}\text { Pouca } \\
\text { utilização }\end{array}$ & $\begin{array}{l}\text { Razoável } \\
\text { utilização }\end{array}$ & $\begin{array}{c}\text { Forte } \\
\text { utilização }\end{array}$ & $\begin{array}{c}\text { Extrema } \\
\text { utilização }\end{array}$ \\
\hline $\begin{array}{l}\text { Fomentar } \\
\text { a } \\
\text { qualidade } \\
\text { das teses e } \\
\text { das } \\
\text { dissertaçõ } \\
\text { es }\end{array}$ & $\begin{array}{l}\text { Manutenç } \\
\text { ão }\end{array}$ & $0,00 \%$ & $2,44 \%$ & $2,44 \%$ & $9,76 \%$ & $43,90 \%$ & $41,46 \%$ \\
\hline $\begin{array}{l}\text { Fortalecer } \\
\text { política de } \\
\text { cooperaçã } \\
\text { o } \\
\text { interinstit } \\
\text { ucional }\end{array}$ & $\begin{array}{l}\text { Manutenç } \\
\text { ão }\end{array}$ & $0,00 \%$ & $0,00 \%$ & $2,44 \%$ & $9,76 \%$ & $46,34 \%$ & $41,46 \%$ \\
\hline $\begin{array}{l}\text { Inserir } \\
\text { programa } \\
\text { de bolsas } \\
\text { estudante } \\
\text { - convênio } \\
\text { de pós- } \\
\text { graduação } \\
\text { - Capes }\end{array}$ & $\begin{array}{l}\text { Manutenç } \\
\text { ão }\end{array}$ & $2,44 \%$ & $2,44 \%$ & $2,44 \%$ & $21,95 \%$ & $29,27 \%$ & $41,46 \%$ \\
\hline $\begin{array}{l}\text { Desenvolv } \\
\text { er e } \\
\text { capacitar o } \\
\text { corpo } \\
\text { docente }\end{array}$ & $\begin{array}{l}\text { Manutenç } \\
\text { ão }\end{array}$ & $2,44 \%$ & $2,44 \%$ & $0,00 \%$ & $21,95 \%$ & $34,15 \%$ & $39,02 \%$ \\
\hline $\begin{array}{l}\text { Incluir } \\
\text { bolsas de } \\
\text { doutorado } \\
\text { sanduíche } \\
\text { no } \\
\text { exterior - } \\
\text { Capes, } \\
\text { e/ou de } \\
\text { pós- } \\
\text { doutorado }\end{array}$ & $\begin{array}{l}\text { Desenvolv } \\
\text { imento }\end{array}$ & $4,88 \%$ & $0,00 \%$ & $4,88 \%$ & $19,51 \%$ & $34,15 \%$ & $36,59 \%$ \\
\hline $\begin{array}{l}\text { Atrair } \\
\text { para o } \\
\text { programa } \\
\text { professor } \\
\text { visitante } \\
\text { do } \\
\text { exterior - } \\
\text { Capes }\end{array}$ & $\begin{array}{l}\text { Manutenç } \\
\text { ão }\end{array}$ & $2,44 \%$ & $0,00 \%$ & $4,88 \%$ & $4,88 \%$ & $56,10 \%$ & $31,71 \%$ \\
\hline $\begin{array}{l}\text { Criar } \\
\text { métricas } \\
\text { que visem } \\
\text { ampliar a } \\
\text { qualidade } \\
\text { e } \\
\text { desempen } \\
\text { ho do } \\
\text { stricto } \\
\text { sensu }\end{array}$ & $\begin{array}{l}\text { Manutenç } \\
\text { ão }\end{array}$ & $0,00 \%$ & $0,00 \%$ & $2,44 \%$ & $17,07 \%$ & $48,78 \%$ & $31,71 \%$ \\
\hline $\begin{array}{l}\text { Ter maior } \\
\text { profission } \\
\text { alismo do } \\
\text { programa } \\
\text { stricto } \\
\text { sensu }\end{array}$ & $\begin{array}{l}\text { Manutenç } \\
\text { ão }\end{array}$ & $0,00 \%$ & $0,00 \%$ & $2,44 \%$ & $12,20 \%$ & $53,66 \%$ & $31,71 \%$ \\
\hline $\begin{array}{l}\text { Criar um } \\
\text { setor } \\
\text { específico } \\
\text { para a } \\
\text { internacio } \\
\text { nalização }\end{array}$ & $\begin{array}{l}\text { Desenvolv } \\
\text { imento }\end{array}$ & $0,00 \%$ & $0,00 \%$ & $0,00 \%$ & $21,95 \%$ & $46,34 \%$ & $31,71 \%$ \\
\hline $\begin{array}{l}\text { Fazer } \\
\text { parcerias } \\
\text { com } \\
\text { outras } \\
\text { IESs de } \\
\text { outras } \\
\text { regiōes/pa } \\
\text { íses, } \\
\text { criando } \\
\text { Minters e } \\
\text { Dinters }\end{array}$ & $\begin{array}{l}\text { Manutenç } \\
\text { ão }\end{array}$ & $2,44 \%$ & 2,44 & $0,00 \%$ & $12,20 \%$ & $53,66 \%$ & $29,27 \%$ \\
\hline
\end{tabular}

Fonte: Dados da pesquisa 
No que se refere à estratégia "Criar um setor específico para a internacionalização", é importante que os programas de stricto sensu invistam em recursos na internacionalização dos seus cursos de pós-graduação, na interação institucional, recompensando aqueles que tiverem fluxo in e out bound de discentes e docentes / pesquisadores, projetos de pesquisa científica em conjuntos, discentes com dupla titulação, disciplinas conjuntas, oferta de cursos em inglês e outras línguas, dentre outras iniciativas e, sobretudo, resultados estruturados e expressos em resultados avaliativos e impactos, seja para o desenvolvimento de políticas institucionais, seja da perspectiva científica, econômica e cultural ao país (Capes, 2018).

\subsection{Clusters das estratégias no cenário oti- mista}

A Tabela 4 evidencia as estratégias por meio de clusters do cenário otimista. Os resultados mostram que a estratégia que melhor discrimina os clusters no cenário otimista é "Buscar empréstimos para expansão por meio de instituições financeiras nacionais". Ainda com a ideia de expandir, a segunda que melhor discrimina é a "Participar de fusão ou aquisição de IES". Também é importante salientar as estratégias: (a) Incorporar necessidades e desafios, em particular, em cada região do país; (b) Implementar programas de qualidade com certificação; (c) Abrir o capital por lançamento de ações (mercado primário de ações) da IES; (d) Capacitar o universo docente em regiões menos favorecidas; (e) Inserir novos sócios nos negócios das IES's; (f) Implantar unidades em outros estados do Brasil; (g) Desenvolver programa institucional de créditos acadêmicos ofertados no exterior; e (h) Negociar com grupos de interesses institucionais.

Dentre as 10 estratégias em realce nesta subseção, seis são vinculadas à postura de Crescimento, duas inerentes à postura de Desenvolvimento e duas com link na postura de Sobrevivência. Tal fato mostra a preocupação dos programas stricto sensu analisados no cenário otimista em focar em estratégias que possibilitem aos referidos programas, e, consequentemente, suas respectivas IES's, alargar e robustecer as atividades e a envergadura destes programas em suas respectivas regiões de alcance, ou até mesmo em outras regiões do Brasil (Moro et al., 2014).

Com isso, reitera-se, entende-se e compreende-se ser essencial a interação orgânica dos programas de stricto sensu com setores não acadêmicos, sobretudo os que são conectados com o processo de transferência direta do conhecimento para a sociedade, influenciando diretamente no processo de aperfeiçoamento socioeconômico e na mitigação das assimetrias regionais no que concerne o conhecimento científico de regiões menos favorecidas no Brasil (CAPES, 2018). 
Tabela 4: Cluster k-means - ranking das estratégias que melhor discriminam os cenários Otimista

\begin{tabular}{|c|c|c|c|c|c|c|c|}
\hline \multirow[b]{2}{*}{ Estratégias } & \multirow{2}{*}{ Posturas } & \multirow{2}{*}{$\begin{array}{l}\text { Cluster } \\
\text { Quadrado } \\
\text { Médio } \\
\end{array}$} & \multirow{2}{*}{\multicolumn{3}{|c|}{$\begin{array}{c}\text { Erro } \\
\text { Quadrado }\end{array}$}} & \multirow[t]{2}{*}{$\mathbf{Z}$} & \multirow[t]{2}{*}{ Sig. } \\
\hline & & & & & & & \\
\hline $\begin{array}{l}\text { Buscar empréstimos para expansão por } \\
\text { meio de instituiçôes financeiras nacionais } \\
\text { - Otimista }\end{array}$ & Crescimento & 45,05 & 2 & 0,78 & 38 & 57,61 & 0,00 \\
\hline $\begin{array}{l}\text { Participar de fusão ou aquisição de IES - } \\
\text { Otimista }\end{array}$ & Crescimento & 35,01 & 2 & 0,93 & 38 & 37,47 & 0,00 \\
\hline $\begin{array}{l}\text { Incorporar necessidades e desafios, em } \\
\text { particular, em cada regiâo do país - } \\
\text { Otimista }\end{array}$ & Crescimento & 30,84 & 2 & 1,18 & 38 & 26,18 & 0,00 \\
\hline $\begin{array}{l}\text { Implementar programas de qualidade } \\
\text { com certificação - Otimista }\end{array}$ & Crescimento & 20,51 & 2 & 1,20 & 38 & 17,02 & 0,00 \\
\hline $\begin{array}{l}\text { Abrir o capital por lançamento de açōes } \\
\text { (mercado primário de ações) da IES - } \\
\text { Otimista }\end{array}$ & Desenvolvimento & 23,24 & 2 & 1,47 & 38 & 15,85 & 0,00 \\
\hline $\begin{array}{l}\text { Capacitar o universo docente em regiôes } \\
\text { menos favorecidas - Otimista }\end{array}$ & Crescimento & 24,78 & 2 & 1,74 & 38 & 14,27 & 0,00 \\
\hline $\begin{array}{l}\text { Inserir novos sócios nos negócios das } \\
\text { IESs- Otimista }\end{array}$ & Sobrevivência & 25,12 & 2 & 1,79 & 38 & 14,00 & 0,00 \\
\hline $\begin{array}{l}\text { Implantar unidades em outros Estados do } \\
\text { Brasil - Otimista }\end{array}$ & Crescimento & 19,76 & 2 & 1,44 & 38 & 13,76 & 0,00 \\
\hline $\begin{array}{l}\text { Desenvolver programa institucional de } \\
\text { créditos académicos ofertados no } \\
\text { exterior - Otimista }\end{array}$ & Desenvolvimento & 11,78 & 2 & 1,02 & 38 & 11,57 & 0,00 \\
\hline $\begin{array}{l}\text { Negociar com grupos de interesses } \\
\text { institucionais - Otimista }\end{array}$ & Sobrevivência & 18,48 & 2 & 1,67 & 38 & 11,07 & 0,00 \\
\hline Imitar modelos institucionais - Otimista & Manutenção & 15,56 & 2 & 1,51 & 38 & 10,32 & 0,00 \\
\hline $\begin{array}{l}\text { Desenvolver doutorado acadêmico ou } \\
\text { profissional internacional ou mestrado } \\
\text { acadêmico ou profissional internacional } \\
\text { ou pós-doutorado - Otimista }\end{array}$ & Desenvolvimento & 9,53 & 2 & 1,04 & 38 & 9,18 & 0,00 \\
\hline $\begin{array}{l}\text { Incluir bolsas de doutorado sanduíche no } \\
\text { exterior - Capes, e/ou de pós-doutorado } \\
\text { - Otimista }\end{array}$ & Desenvolvimento & 10,10 & 2 & 1,11 & 38 & 9,10 & 0,00 \\
\hline $\begin{array}{l}\text { Criar métricas que visem ampliar a } \\
\text { qualidade e o desempenho do stricto } \\
\text { sensu- Otimista }\end{array}$ & Manutençāo & 3,51 & 2 & 0,44 & 38 & 8,03 & 0,00 \\
\hline $\begin{array}{l}\text { Desenvolver e capacitar o corpo docente } \\
\text { - Otimista }\end{array}$ & Manutenção & 7,13 & 2 & 0,94 & 38 & 7,58 & 0,00 \\
\hline $\begin{array}{l}\text { Diminuir o número de cursos de stricto } \\
\text { sensu- Otimista }\end{array}$ & Sobrevivência & 6,20 & 2 & 0,85 & 38 & 7,28 & 0,00 \\
\hline $\begin{array}{l}\text { Expandir o campus em unidades fora da } \\
\text { sede (no mesmo municipio ou no } \\
\text { interior) - Otimista }\end{array}$ & Crescimento & 14,66 & 2 & 2,31 & 38 & 6,34 & 0,00 \\
\hline Reposicionar a Marca da IES - Otimista & Manutenção & 12,01 & 2 & 1,90 & 38 & 6,33 & 0,00 \\
\hline $\begin{array}{l}\text { Aperfeiçoar a internacionalização na } \\
\text { formaçấo do pessoal do ensino superior } \\
\text { no Brasil - Otimista }\end{array}$ & Desenvolvimento & 3,42 & 2 & 0,57 & 38 & 6,03 & 0,01 \\
\hline $\begin{array}{l}\text { Investir em negócios não relacionados } \\
\text { com a IES (em outras empresas) - } \\
\text { Otimista }\end{array}$ & Desenvolvimento & 8,47 & 2 & 1,51 & 38 & 5,60 & 0,01 \\
\hline $\begin{array}{l}\text { Atrair para o programa professor } \\
\text { visitante do exterior - Capes - Otimista }\end{array}$ & Manutenção & 4,34 & 2 & 0,79 & 38 & 5,48 & 0,01 \\
\hline Terceirizar as áreas logisticas - Otimista & Manutençāo & 9,42 & 2 & 1,78 & 38 & 5,29 & 0,01 \\
\hline $\begin{array}{l}\text { Inserir programa de bolsas estudante - } \\
\text { convênio de pós-graduaçấo - Capes - } \\
\text { Otimista }\end{array}$ & Manutenção & 5,88 & 2 & 1,14 & 38 & 5,18 & 0,01 \\
\hline $\begin{array}{l}\text { Lançar novos cursos de stricto sensu em } \\
\text { outras áreas análogas a administração, } \\
\text { contabilidade e ou turismo - Otimista }\end{array}$ & Crescimento & 6,95 & 2 & 1,59 & 38 & 4,36 & 0,02 \\
\hline
\end{tabular}

\section{Fonte: Dados da pesquisa}




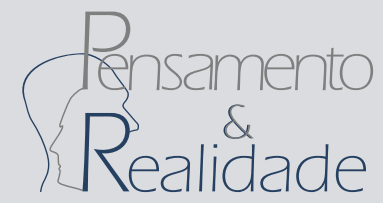

\begin{tabular}{|c|c|c|c|c|c|c|c|}
\hline $\begin{array}{l}\text { Aumentar o número de cursos de stricto } \\
\text { sensu- Otimista }\end{array}$ & Crescimento & 6,97 & 2 & 1,68 & 38 & 4,14 & 0,02 \\
\hline $\begin{array}{l}\text { Importar pessoas influentes } \\
\text { (pesquisadores, gestores, docentes) - } \\
\text { Otimista }\end{array}$ & Manutenção & 4,75 & 2 & 1,20 & 38 & 3,95 & 0,03 \\
\hline $\begin{array}{l}\text { Aperfeiçoar e difundir a proposta do } \\
\text { programa - Otimista }\end{array}$ & Manutençâo & 4,91 & 2 & 1,26 & 38 & 3,90 & 0,03 \\
\hline $\begin{array}{l}\text { Fomentar a qualidade das teses e das } \\
\text { dissertacoôes - Otimista }\end{array}$ & Manutençâo & 2,68 & 2 & 0,71 & 38 & 3,76 & 0,03 \\
\hline $\begin{array}{l}\text { Fortalecer política de cooperaçâo } \\
\text { interinstitucional - Otimista }\end{array}$ & Manutençâo & 1,73 & 2 & 0,49 & 38 & 3,53 & 0,04 \\
\hline $\begin{array}{l}\text { Fazer parcerias com outras IESs de } \\
\text { outras regiōes/paises, criando Minters e } \\
\text { Dinters - Otimista }\end{array}$ & Manutençâo & 3,29 & 2 & 0,93 & 38 & 3,52 & 0,04 \\
\hline $\begin{array}{l}\text { Consolidar relacionamentos } \\
\text { interinstitucionais por meio de } \\
\text { programas permanentes de dupla } \\
\text { titulação em nivel de mestrado e } \\
\text { doutorado - Otimista }\end{array}$ & Desenvolvimento & 2,72 & 2 & 0,78 & 38 & 3,48 & 0,04 \\
\hline $\begin{array}{l}\text { Incentivar e ou inserir o foco cultural, } \\
\text { ecológica e social de relevância da IES - } \\
\text { Otimista }\end{array}$ & Desenvolvimento & 4,48 & 2 & 1,29 & 38 & 3,47 & 0,04 \\
\hline $\begin{array}{l}\text { Violar as fontes de pressão institucional - } \\
\text { Otimista }\end{array}$ & Sobrevivência & 4,42 & 2 & 1,34 & 38 & 3,31 & 0,05 \\
\hline $\begin{array}{l}\text { Investir em Marketing no programa } \\
\text { stricto sensu - Otimista }\end{array}$ & Manutençâo & 3,89 & 2 & 1,26 & 38 & 3,10 & 0,06 \\
\hline $\begin{array}{l}\text { Perder o controle acionário/patrimonial } \\
\text { da IES, impactando no programa stricto } \\
\text { sensu - Otimista }\end{array}$ & Sobrevivência & 5,36 & 2 & 1,85 & 38 & 2,90 & 0,07 \\
\hline $\begin{array}{l}\text { Mudar objetivos, atividades ou dominios - } \\
\text { Otimista }\end{array}$ & Sobrevivência & 4,50 & 2 & 1,71 & 38 & 2,64 & 0,08 \\
\hline $\begin{array}{l}\text { Formar de maneira adequada o aluno no } \\
\text { seu desenvolvimento profissional - } \\
\text { Otimista }\end{array}$ & Manutençẫo & 0,87 & 2 & 0,45 & 38 & 1,93 & 0,16 \\
\hline $\begin{array}{l}\text { Planejar programas estratégicos } \\
\text { especificos - Otimista }\end{array}$ & Manutençâo & 1,12 & 2 & 0,63 & 38 & 1,79 & 0,18 \\
\hline $\begin{array}{l}\text { Ter maior profissionalismo do programa } \\
\text { stricto sensu - Otimista }\end{array}$ & Manutençâo & 0,80 & 2 & 0,51 & 38 & 1,56 & 0,22 \\
\hline $\begin{array}{l}\text { Fomentar a reputaçâo do programa } \\
\text { stricto sensu, mediante a atuação do } \\
\text { egresso do programa na sociedade - } \\
\text { Otimista }\end{array}$ & Desenvolvimento & 1,13 & 2 & 0,76 & 38 & 1,49 & 0,24 \\
\hline Contestar regras e exigências - Otimista & Sobrevivência & 2,49 & 2 & 2,07 & 38 & 1,20 & 0,31 \\
\hline $\begin{array}{l}\text { Criar um setor específico para a } \\
\text { internacionalização - Otimista }\end{array}$ & Desenvolvimento & 0,61 & 2 & 0,54 & 38 & 1,15 & 0,33 \\
\hline $\begin{array}{l}\text { Dominar públicos e processos } \\
\text { institucionais - Otimista }\end{array}$ & Desenvolvimento & 1,63 & 2 & 1,57 & 38 & 1,03 & 0,37 \\
\hline $\begin{array}{l}\text { Alargar a exigência para produção } \\
\text { cientifica por parte dos professores que } \\
\text { podem ser credenciados com o perfil } \\
\text { acadêmico ou profissional, respeitando os } \\
\text { limites impostos pelo sistema - Otimista }\end{array}$ & Desenvolvimento & 0,78 & 2 & 0,76 & 38 & 1,03 & 0,37 \\
\hline $\begin{array}{l}\text { Aperfeiçoar as linhas de pesquisa do } \\
\text { programa stricto sensu - Otimista }\end{array}$ & Manutençâo & 0,67 & 2 & 1,66 & 38 & 0,40 & 0,67 \\
\hline $\begin{array}{l}\text { Fazer com que o programa stricto sensu } \\
\text { necessite atender às necessidades dos } \\
\text { stakeholders - Otimista }\end{array}$ & Desenvolvimento & 0,34 & 2 & 1,65 & 38 & 0,21 & 0,82 \\
\hline
\end{tabular}

Nesse contexto, reforça-se ao afirmar que em um ambiente de desafios as instituições, governo e sociedade podem e devem usar a prospecção de cenário para auxiliar tais instituições e seus respectivos programas de pós-graduação stricto sensu, identificando suas principais variáveis socioeconômicas, mensageiras do futuro, organizando-as para as várias probabilidades de eventos futuros, oferecendo-lhes condições para tomadas de decisões mais estratégicas e proativas, com maior efetividade e, por conseguinte, tornando-as capazes à formulação de um planejamento estratégico empresarial coerente, harmônico 
e com a imperativa visão de futuro (Wright \& Goodwin, 1999; Godet, 2010; Moritz et al., 2013; Morais, Forte \& Oliveira, 2015; Ithnin et al., 2018).

Tal afirmação é corroborada no estudo de Richards, O'Shea e Connolly (2004), pois constataram que a metodologia de cenários é uma ferramenta útil para que as instituições de ensino superior desenvolvam e implementem estratégias competitivas capazes de contribuir positivamente para os negócios em ambientes externos frequentemente mutáveis.

\subsubsection{Clusters das estratégias no cenário otimista (dendograma à luz dos respon- dentes)}

A Figura 5 vislumbra o dendograma do cluster hierárquico das estratégias do cenário otimista sob a ótica dos respondentes.

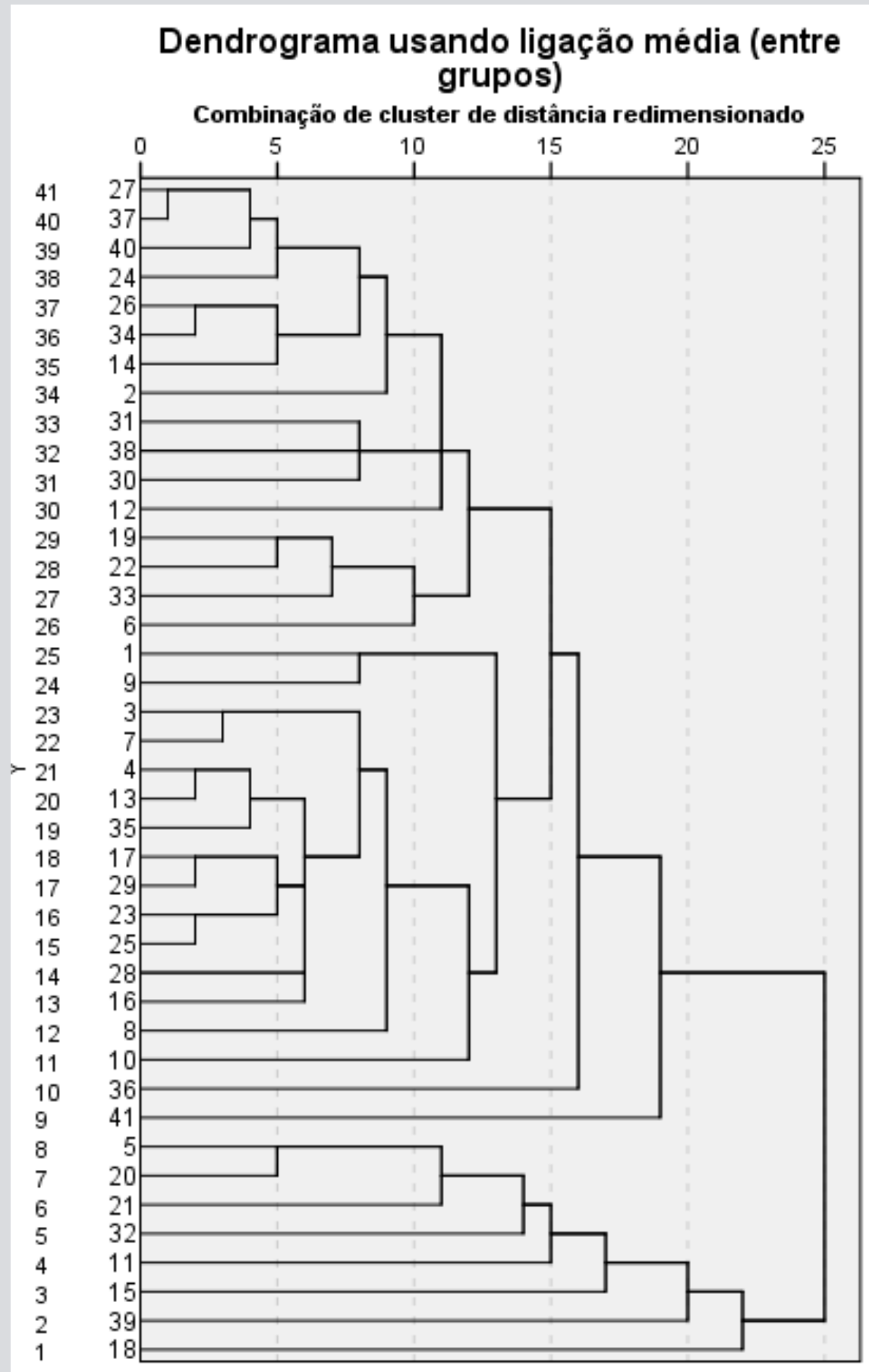

Figura 5: Dendograma do cluster hierárquico do cenário otimista (respondentes)

Fonte: Dados da pesquisa 


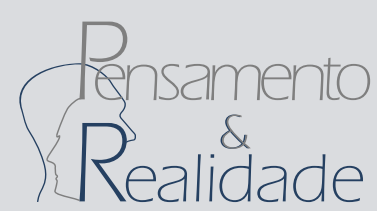

Analisando a Figura 5, observa-se a existência de dois clusters, o primeiro indo do respondente 27 até o 41 , e o segundo do respondente 5 ao 18 . Isso mostra pouca diversidade de respostas entre os respondentes no que tange ao cenário otimista. Tal fato pode ser explicado, em razão do cenário otimista vislumbrar as estratégias que proporcionam médias e altas expectativas de virem a acontecer, estas serão (caso ocorram) mediana ou altamente apropriadas para os programas de pós-graduação ora analisados (Figueiredo, Chedid \& Machado Neto, 2010; Spada \& Forte, 2018).

\subsubsection{Clusters das estratégias no cenário otimista (dendograma das estratégias)}

A Figura 6 evidencia o dendograma das estratégias competitivas para o cenário otimista.

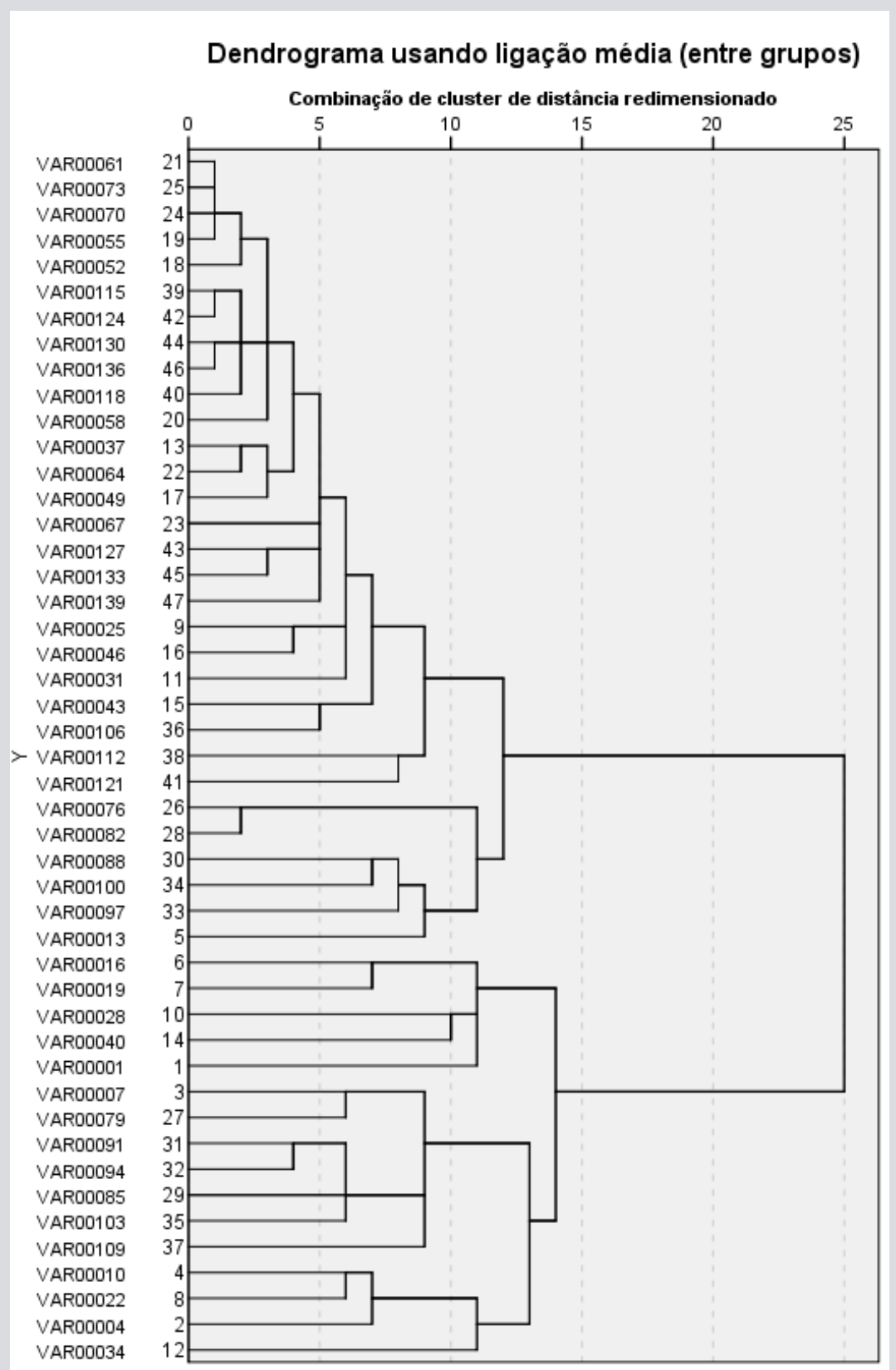

Figura 6: Dendograma das estratégias competitivas para o cenário otimista

Fonte: Dados da pesquisa

* Eixo X - apresenta as distâncias euclidiana de um item até outro numa escala de 0 a 25; e Eixo $\mathrm{Y}$ - apresentam as estratégias competitivas 
Da mesma forma que foi conduzida a criação de dendogramas para o cenário otimista de cluster hierárquico foi também administrado a criação de dendogramas das estratégias para cada cenário otimista. Tais cenários indicaram a formação de clusters dentro dos próprios cenários, isto é, observando a formação e grupos distintos entre as estratégias dos respectivos cenários. A combinação de cluster de distância entre a escala 20 e 25 é o trecho onde o recorte indica a formação de dois clusters para o cenário. Um cluster com mais estratégias e outro cluster com o restante das estratégias. Pode ser inferido que no referido cenário há a formação de clusters, indicando diferentes opiniões dentro deste cenário.

Tal panorama pode ser explicado, pois o cenário otimista para este estudo pode ser composto por estratégias que acomodam alta perspectiva de ocorrência e que são muito aderentes para os programas de pós-graduação ora analisados neste estudo. Posto isto, é preponderante que os programas de stricto sensu objeto de estudo procurem formular, adotar e implementar estratégias competitivas para futuro cenário otimista para sustentar ou conseguir as notas de excelência da CAPES.

Tal ação poderá influenciar no maior incentivo à publicação de qualidade, auxiliado, embasado e orientado por um corpo professores/pesquisadores de alto desempenho, sendo isto visto como recurso estratégico ímpar e que gera vantagem competitiva sustentável, fazendo surgir, a posteriori, recursos estratégicos valiosos, raros, de difícil ou demorada imitação e substituição, fazendo com que os programas em análise tornem-se bem administrados no âmbito nacional e, quiçá no contexto internacional, propiciando com isso que os programas alcancem a internacionalização (Moritz et al., 2013; Capes, 2016).

\section{Conclusão}

O objetivo deste estudo foi identificar as estratégias mais prováveis pelos Programas de Stricto Sensu das Instituições de Ensino Superior do Brasil da área de Administração Pública e de Empresas, Ciências Contábeis e Turismo frente cenário otimista prospectado para o período de 2019 a 2030, embasada pela metodologia sugerida por Blanning e Reinig (1998). Os principais resultados mostram que quanto à utilização das estratégias por cenário, as estratégias "fortalecer política de cooperação interinstitucional" e "fomentar a qualidade das teses e das dissertações" ficaram em destaque no cenário otimista.

Em relação ao uso extremo das estratégias no cenário otimista, realça-se o item "fomentar a qualidade das teses e das dissertações", confirmando sua importância na média de sua utilização. É importante salientar que, ao enfatizar a estratégia da qualidade das teses e das dissertações, se enfocam também o corpo docente-discente, da produção científica, e da eficiência e eficácia dos programas de pós-graduação stricto sensu na formação de novos mestres e doutores (Crespi et al., 2017).

Em relação às estratégias por cenário mediante os clusters, constatou-se que, para os cenário otimista, as estratégias que ficaram em ênfase foram: "buscar empréstimos para expansão por meio de instituições financeiras nacionais" e "participar de fusão ou aquisição de IES”, mostrando assim que as citadas estratégias adequam-se ou harmonizam-se de acordo com cenários alternativos (Blass, Thornton \& Rawlings, 2011).

Ponderando a carência de pesquisas referentes à questão de pesquisa que embasou e norteou este trabalho, este estudo contribui para viabilizar as estratégias mais prováveis para os programas de stricto sensu das IESs do Brasil da área de administração pública e de empresas, ciências contábeis e turismo frente ao cenário otimista prospectado para o período de 2019 a 2030, influenciando na formulação e implementação destas (Lindgren \& 
Bandhold, 2003; Heinzen \& Marinho, 2019) nas instituições públicas e ou privadas, e, consequentemente, em seus respectivos programas de pós-graduação stricto sensu, alicerçado em uma análise prospectiva de cenários prováveis (Hicks \& Gidley, 2012).

Outra contribuição que este estudo traz para a literatura científica da área é trazer em pauta um alargado e robusto número de estratégias que poderão viabilizar contribuições importantes para as IESs e seus respectivos programas de pós-graduação stricto sensu da área de administração, contabilidade e turismo em cenários de incertezas (Postma \& Liebl, 2005; Maggs \& Chelin, 2013) e desafios em decorrência da competitividade (Heinzen \& Marinho, 2019), perseguindo e alçando a posteriori melhores níveis de performance organizacional (Fernandes, Fleury \& Mills, 2006).

De maneira geral, o que se espera dos programas de pós-graduação stricto sensu no Brasil para 2030 é que ela aja com uma consciência estratégica alargada e robusta, atentando às condições para performar a aprendizagem humana do futuro, por meio de uma atuação mais pujante e conjunta dos docentes(pesquisadores)/discentes/gestores/ instituições contribuindo para o fomento da qualidade da pesquisa nos mestrados e doutorados, e, concomitantemente, colaborando diretamente na qualificação sólida de novos e diferentes egressos, impactando em uma maior inserção social, cooperação interinstitucional e crescimento da qualidade da produção científica do conhecimento da área em análise neste estudo.

A limitação do estudo deu-se em virtude do número reduzido de entrevistas na primeira etapa, contudo, as mesmas foram robustas e alargadas, ajudando assim na continuidade das etapas posteriores do estudo, e, consequentemente na resposta e no alcance da questão e no objetivo do estudo concomi- tantemente. Seguem adiante algumas sugestões para estudos futuros: (i) replicar o referido estudo, abarcando, não somente a área de administração pública e de empresas, ciências contábeis e turismo, mas também, outros campos do saber; (ii) contrapor o citado estudo, agora, ampliando o foco para o exterior, e, consequentemente e a posteriori, vislumbrar análises comparativas entre o âmbito nacional e o internacional; (iii) complementar o mencionado estudo, agora, robustecendo a análise, mediante uma pesquisa qualitativa, buscando, com isso, melhor entender o uso de possíveis estratégias mais realçadas nesta pesquisa, podendo, usar os métodos de grupo focal e ground theory; e (iv) criar um modelo para melhor compreender os cenários alternativos com desígnios díspares que foram concebidos e manifestados neste estudo.

\section{Referências}

Azevedo, M. C. de, \& Costa, H. G. (2010). Métodos para avaliação da postura estratégica. Revista de Gestão da USP, 8(2).

Barney, J. (1991). Firm resources and sustained competitive advantage. Journal of Management, 17(1), 99-120.

Bertero, C. O., Caldas, M. P., \& Wood Jr, T. (1999). Produção científica em administração de empresas: provocações, insinuações e contribuições para um debate local. Revista de Administração Contemporânea, 3(1), 147-178.

Blanning, R. W., \& Reinig, B. A. (1998). Building scenarios for Hong Kong using EMS. Long Range Planning, 31(6), 900-910.

Blass, E., Thornton, M., \& Rawlings, B. (2011). Future scenarios for a depressed region of England: the role of education in creating alternative futures. Foresight, 13(6), 3-17.

Cirani, C. B. S., Campanario, M. de A., \& Silva, H. H. M. da. (2015). A evolução do ensino da pósgraduação senso estrito no Brasil: análise exploratória e proposições para pesquisa. Avaliação, 20(1), 163187.

Coordenação de Aperfeiçoamento de Pessoal de Nível Superior - CAPES. Documento de área: Administração Pública e de Empresas, Ciências Contábeis e Turismo. Recuperado em: < http://www.capes.gov.br/>.

Coordenação de Aperfeiçoamento de Pessoal de Nível Superior - CAPES. Proposta de aprimoramento do modelo de avaliação da PG: documento final 
da Comissão Nacional de Acompanhamento do PNPG 2011-2020 - 10/10/2018. Recuperado em: <file://C:/Users/hcmri/Downloads/PNPG\%20CS\%20 Avaliac\%C3\%A3o_Final_10\%2010\%2018_CS FINAL_17_55.pdf $>$.

Crespi, T. B. et al. (2017). Novo qualis: impacto na avaliação da produção intelectual dos pesquisadores em administração. Revista de Ciências da Administração, 19(47), 131-147.

Faller, L. P., \& Almeida, M. I. R. de. (2014). Planejamento por cenários: preparando pequenas empresas do varejo de móveis planejados para um futuro competitivo. Revista de Administração da USP, 49(1), 171-187.

Fernandes, B. H. R., Fleury, M. T. L., \& Mills, J. (2006). Construindo o diálogo entre competência, recursos e desempenho organizacional. Revista de Administração de Empresas, 46(4), 48-65.

Figueiredo, E. F., Chedid, S. E., \& Machado Neto, A. J. (2010). Cenários e orçamento empresarial: aplicação prática da metodologia de prospecção no Magazine Luiza. Anais... In: Encontro de Pesquisadores do UniFACEF - Centro Universitário de Franca, 11.

Gaspar, M. A., \& Campos, D. C. S. (2015). Estudo da produtividade de doutores egressos do PPGA FEA-USP. Revista da Faculdade de Administração e Economia, 6(2), 14-32.

Godet, M. (2010). Future memories. Technological Forecasting and Social Change, 77(9), 1457-1463.

Gonçalves, M. S. (2011). Análise dos aspectos internos, do ambiente externo e elaboração de cenários como base para a definição das estratégias. Dissertação (Mestrado em Engenharia de Produção) - Universidade Federal de Santa Maria (UFSM), Santa Maria.

Goodwin, P., \& Wright, G. (2001). Enhancing strategy evaluation in scenario planning: a role for decision analysis. Journal of Management Studies, 38(1), 1-16. Hall, R. (1992). The strategic analysis of intangible resources. Strategic Management Journal, 13(2), 135 144.

Heinzen, D. A. de M. (2015). Alinhamento entre formulação e implementação da estratégia em Instituição de Ensino Superior, Tese (Doutorado em Administração e Turismo),Univalí,202 pg.

Heinzen, D. A. de M., \& Marinho, S. V. (2018). A construção de cenários para o alinhamento entre formulação e implementação da estratégia. Revista de Ciências da Administração, 20(50), 24-43.

Heinzen, D. A. de M., \& Marinho, S. V. (2019). Alinhamento entre formulação e implementação da estratégia em instituições de ensino superior no Brasil. Organizações em Contexto, 15(29), 279-322.

Hirsch, S., Burggraf, P., \& Daheim, C. (2013). Scenario planning with integrated quantification - managing uncertainty in corporate strategy building. Foresight, 15(5), 363-374.
Hicks, D., \& Gidley, J. (2012). Futures education: Case studies, theories and transformative speculations. Futures, 44(1), 1-3.

Itami, H., \& Roehl, T. (1987). Mobilizing invisible assets. Cambridge, MA: Harvard University.

Leite, J. B. D., \& Porsse, M. de C. S. (2003). Competição baseada em competências e aprendizagem organizacional: em busca da vantagem competitiva. Revista de Administração Contemporânea, 7(SPE), 121-141.

Ithnin, F. et al. (2018). Mappingthe futures of malaysianhigher education: a meta - analysis of futures studies in the Malaysian higher educations cenario. Journal of Futures Studies, 22(3), 1-18.

Lindgren, M., \& Bandhold, H. (2003). Scenario planning. Palgrave.

Maccari, E. A. et al. (2009). A gestão dos programas de pós-graduação em administração com base no sistema de avaliação da Capes. Revista de Gestão USP, 16(4), 01-16.

Maccari, E. A., Lima, M. C., \& Riccio, E. L. (2009). Uso do Sistema de Avaliação da CAPES por Programas de Pós-Graduação em Administração no Brasil. Revista de Ciências da Administração, 11(25), 68-96.

Maccari, E. A., Riccio, E. L., \& Martins, C. B. (2013). A influência do sistema de avaliação da AACSB na gestão dos programas de pós-graduação stricto sensu em Administração nos Estados Unidos. Revista Eletrônica de Administração, 19(3), 738-766.

Maggs, P., \& Chelin, J. (2013). Scenario planning for an uncertain future? Case study of the restructuring of the academic services team at UWE Library. Library Management, 34(8/9), 664-676.

Marcial, E. C., \& Grumbach, R. J. S. (2002). Cenários prospectivos: como construir um futuro melhor. 4.ed. Rio de Janeiro: Editora FGV.

Maroco, J. (2014). Análise estatística com utilização do SPSS. Lisboa: Edições Sílabo.

Martins, C. B. et al. (2013). Utilização da Resource Based-View no desempenho dos programas de pósgraduação stricto sensu em administração, ciências contábeis e turismo no Brasil: um estudo dos programas no período de 2001 a 2009. Anais..., EnANPAD, 37, Rio de Janeiro / RJ.

Meirelles, D. S. E., \& Camargo, Á. A. B. (2014). Capacidades dinâmicas: o que são e como identificálas? Revista de Administração Contemporânea, 18(Edição Especial), 41-64.

Meissner, P., \& Wulf, T. (2013). Cognitive benefits of scenario planning: its impact on biases and decision quality. Technological Forecasting and Social Change, 80(4), 801-814.

Morais, N. M. de, Forte, S. H. A. C., \& Oliveira, M. do C. (2015). Proposição de método para avaliar a maturidade do processo de cenários nas organizações. Revista de Administração Mackenzie, 16(2), 214-244. 
Moritz, G. de O. et al. (2013). A Pós-graduação brasileira: evolução e principais desafios no ambiente de cenários prospectivos. Future Studies Research Journal, 5(2), 03-34.

Moritz, G. de O., Nuner, R., \& Pereira, M. F. (2008). Os métodos de prospecção de cenários e sua aplicação nas organizações: um estudo de caso no período 19982008. Revista de Administração da FACES, 7(2), 6883.

Moro, A. B. et al. (2014). Clima organizacional: fatores significativos na percepção de docentes e discentes vinculados a programas de pós-graduação. Revista Gestão Universitária na América Latina, 7(3), 01-21.

O’Brien, F. A., \& Meadows, M. (2013). Scenario orientation and use to support strategyd evelopment. Technological Forecastingand Social Change, 80(4), 643-656.

Oliveira, O., \& Forte, S. (2009). A indústria bancária brasileira: construindo cenários prospectivos e identificando as estratégias de utilização mais provável. Revista Portuguesa e Brasileira de Gestão, 64-77.

Oliveira, O. V. de et al. (2017). Atirou no que viu, acertou no que não viu. Revista Alcance, 24(1), 129146.

Oliveira, O. V. de, \& Forte, S. H. A. C. (2014). Estratégias e ferramentas competitivas das MPEs na região Nordeste. Revista da Micro e Pequena Empresa, 8(2), 18-37.

Porter, M. E. (1980). Competitive strategy: techniques for analyzing industries and competitors. New York: Free Press.

Porto, C., \& Régnier, K. (2003). O ensino superior no mundo e no Brasil: condicionantes, tendências e cenários para o horizonte 2003-2025: uma abordagem exploratória. Dez.

Postma, T. J. B. M., \& Liebl, F. (2005). How to improve scenario analysis as a strategic management tool? Technological Forecasting \& Social Change, 72, 161-173.

Rao, P. S. R. S. (2013). Sampling methodologies with applications. Boca Raton: Chapman \& Hall/CRC.

Richards, L., O'shea, J., \& Connolly, M. (2004). Managing the concept of strategic change within a higher education institution: the role of strategic and scenario planning techniques. Strategic Change, 13(7), 345-359.

Rieckmann, M. (2012). Future-oriented higher education: which key competencies should be fostered through university teaching and learning? Futures, 44(2), 127-135.
Rocha Neto, I. (2010). Prospectiva da pós-graduação no Brasil (2008 - 2022). Revista Brasileira de PósGraduação, 7(12), 58-79.

Santos, J. E. A. dos, \& Cândido, G. A. (2013). Estrutura de governança em arranjos produtivos locais: uma aplicação no arranjo calçadista no município de Campina Grande/PB. Anais..., Encontro de Estudos em Estratégia, 4, Bento Gonçalves.

Silva, A. T. B. da et al. (2013). Cenários prospectivos para o comércio internacional de etanol em 2020. Revista de Administração da USP, 48(4), 727-738.

Silva, M. C. da, \& Forte, S. H. A. C. (2016). Estratégias de criação de valor compartilhado a serem adotadas diante de cenários prospectados para a indústria da construção civil no Ceará. Future Studies Research Journal, 8(3), 227-254.

Sobreira, M. do C. et al. (2014). Cenários prospectivos no combate ao turismo sexual internacional em Fortaleza. Revista Turismo - Visão e Ação - Eletrônica, 16(2), 416-449.

Sousa, J. R. de, Forte, S. H. A. C., \& Oliveira, O. V. de. (2012). Recursos estratégicos no cenário 2009/2015 das IESS particulares da região nordeste do Brasil. Revista Ibero-Americana de Estratégia, 11(2), 91-119. Scavarda, L. F. R., \& Hamacher, S. (2001). Evolução da cadeia de suprimentos da indústria automobilística no Brasil. Revista de Administração Contemporânea, 5(2), 201-219.

Spada, E., \& Forte, S. H. A. C. (2018). Cenários prospectivos das universidades corporativas no Brasil - 2030. Future Studies Research Journal, 10(2), 198213.

Thiesen, J. da S., Garcez, E. F., \& Guimaraes, J. E. (2014). Prospecção de cenários em educação: dos desafios do presente às possibilidades de futuro. Revista Ibero-Americana de Estudos em Educação, 9(1), 1-17.

Vasconcelos, F. C., \& Cyrino, Á. B. (2000). Vantagem competitiva: os modelos teóricos atuais e a convergência entre estratégia e teoria organizacional. Revista de Administração de Empresas, 40(4), 20-37. Walsh, P. R. (2005). Dealing with the uncertainties of environmental change by adding scenario planning to the strategy reformulation equation. Management Decision, 43(1), 113-122.

Wright, G., \& Goodwin, P. (2009). Decision making and planning under low levels of predictability: Enhancing the scenario method. International Journal of Forecasting, 25(4), 813-825. 


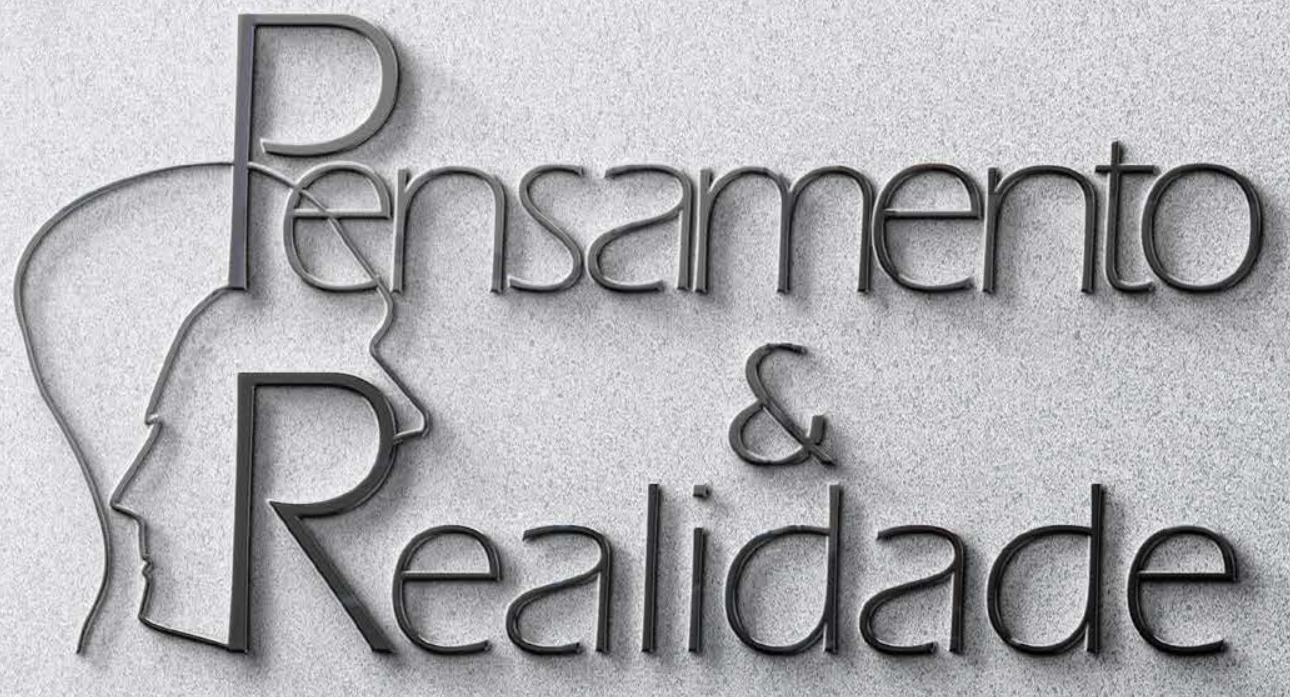

\section{Tonlia destanio no \\ ambiente de doutorado}

1 IITHEI I DII 